Bazyli DEGÓRSKI, O.S.P.P.E.

\title{
UNO SCHIZZO DI ESCATOLOGIA PALEOCRISTIANA
}

L'articolo intende presentare brevemente l'insegnamento primigenio patristico circa gli ultimi eventi escatologici quali la vita nell'aldilà, la seconda venuta di Cristo, la risurrezione dei morti, il giudizio universale e la vita eterna ${ }^{1}$. Sarà preso in considerazione il periodo che va dall'inizio della letteratura patristica sino ai tempi di sant'Agostino $(† 430)$, ossia del cristianesimo ancorato ai tempi e al pensiero dell'antichità, escludendo in tal modo ogni influsso medioevale. Si cercherà, altresì, di tratteggiare un rapporto tra l'escatologia orientale e quella occidentale, cioè - per usare l'espressione di Giovanni Paolo II - l'escatologia dei «due polmoni della Chiesa», nel segno della ricerca dei fattori comuni, peraltro molto consistenti, piuttosto che degli elementi di rottura fra i due mondi teologici, che in realtà avverrà più tardi al periodo da noi mirato. L'intento di evidenziare l'armonia della Chiesa primitiva emerge anche dalla scelta di trattare gli autori latini e greci insieme.

1. Tensione escatologica e concettualità teologica. L'escatologia prima di essere un trattato è stata una realtà esistenziale per i cristiani delle prime generazioni: essi attesero con incontenibile speranza e fiducia la seconda venuta del Signore, creando uno stato di tensione tra «già» e «non ancora», che nell'immediato fu percepito come un'interpretazione della storia e che solo più tardi si trasformò in concezione escatologica nel nostro senso. Dopo la prima generazione dei tempi apostolici, infatti, il cristianesimo allentò l'attesa della parusia e la convinzione di vivere nei tempi messianici cedette il posto all'idea del Regno di Dio come uno stato nel futuro, riservato come ricompensa a tutti coloro che in questa vita terrena vivono virtuosa-

${ }^{1}$ L'articolo costituisce il testo della lezione accademica dallo stesso titolo, tenuta per il corso interdisciplinare: L'Escatologia cristiana verso il Terzo Millennio. Prospettive ecumeniche, organizzato dall'Istituto Superiore di Scienze Religiose «Mater Ecclesiae» della Pontificia Università San Tommaso d'Aquino, tenuto nel primo semestre dell'anno accademico 1997-1998. Il corso fu anche finalizzato all'aggiornamento degli Insegnanti di religione cattolica. 
mente ${ }^{2}$. Ad esempio: san Clemente di Roma ${ }^{3}$ parla di san Pietro e di san Paolo e di altri cristiani ai quali è stato assegnato in cielo un premio per le fatiche subite sulla terra ${ }^{4}$; l'autore anonimo della cosiddetta «Seconda lettera di Clemente», invece, insegna che il premio eterno viene ottenuto grazie alle opere buone e caritatevoli ${ }^{5}$; san Giustino considera il Regno di Dio come ricompensa dopo la morte per una condotta virtuosa sulla terra ${ }^{6}$. Anche Tertulliano sostiene che il Signore tornerà gloriosamente per condurre i suoi fedeli alla ricompensa della vita eterna ove godranno dei benefici celesti ${ }^{7}$.

Come possiamo constatare, i cristiani dell'età post-apostolica si muovono verso una visione di Dio come colui che distribuisce con giustizia o la punizione o la ricompensa. E anche la grazia perde il significato escatologico che possiede nel Nuovo Testamento e diventa qualche cosa che deve essere ottenuto.

Nei primi secoli, però, rimane nella coscienza dei cristiani anche la certezza primitiva di godere già dei benefici della vita celeste. Infatti, nel battesimo i fedeli ricevono già su questa terra la garanzia della ricompensa. Essi vengono

${ }^{2}$ Per quanto riguarda il problema della tensione verso l'eschaton e la concezione escatologica dei primi secoli, cf. L. Atzberger, Geschichte der christlichen Eschatologie innerhalb der vornicänischen Zeit, Freiburg i.B. 1896; G. Florowski, Eschatology in the Patristic Age, in: Studia Patristica, Bd. 2, Berlin 1957, 235-250; C.F.D. Moule, The influence of circumstances on the use of eschatological terms, JTS 15(1964) 1-15; J. Carmignac, Les dangers de l'eschatologie, „New Testament Studies” 17(1971) 365-390; R. Žužek, La transfiguración escatológica del mundo, OCP 37(1971) 182-222; J.N.D. Kelly, Il pensiero cristiano delle origini, Bologna 1972, 559-562; A.C. Rush, Death as a spiritual Marriage. Individual and Ecclesiastical Eschatology, VigCh 26(1972) 81-101; J.L. Ruiz de la Peña, La oltra dimensión. Escatología cristiana, Madrid 1975 (tr.it. Assisi 1981); AA.VV., Studi sull'escatologia. VI incontro di studiosi dell'antichità cristiana (Roma, maggio 1977) - numero speciale di „Augustinianum” 18(1978); AA.VV., Mysterium salutis, XI, Brescia 1978; J. Carmignac, Le mirage de l'eschatologie, Paris 1979; A. Fernández, La escatología en el siglo II, Burgos 1979; G. Filoramo, Escatologia, DPAC I 1204-1211.

${ }^{3}$ Per quanto riguarda l'escatologia dei Padri Apostolici, cf. A. Fernández, La escatología en los escritos de los Padres Apostólicos, „Burgense” 20(1979) 9-55; T. Kaczmarek, Los sprawiedliwego Starego Testamentu po śmierci według świadectw z I/II w. VoxP 10(1990) t. 19, 589-597.

${ }^{4}$ Cf. Clemens Romanus, Prima epistula ad Corinthios 5.

Cf. Pseudo Clemens Romanus, Epistula secunda ad Corinthios 9 (cf. anche, ibidem, 6).

${ }^{6}$ Cf. Iustinus, Dialogus cum Tryphone 117,3; idem, Prima apologia 14,3. Per quanto riguarda la visione escatologica di san Giustino, cf. G. Archambault, Le témoignage de l'ancienne littérature

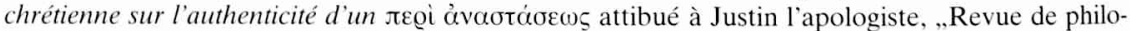
logie" 29(1905) 73-93; H.I. Marrou, La résurrection des morts et les Apologistes des premiers siècles, „Lumière et Vie” 3(1952) 83-92; L.W. Barnard, Justin Martyr's Eschatology, VigCh 19(1965) 86-98; A.O. Wieland, Die Eschatologie Justins des Philosophen und Märtyrers. Eine Untersuchung zum Standort und zur Bedeutung der Eschatologie bei den griechischen Apologeten des 2. Jahrhunderts, Innsbruck 1969; V. Grossi, Lineamenti di antropologia patristica, Roma 1983, 122-125; M. Maritano, Giustino Martire di fronte al problema della metempsicosi (Dial. 4, 4-7 e 5, 5), „Salesianum” 53(1992) 231-281.

7 Cf. Tertullianus, De praescriptione haereticorum 13. Cf. anche V.C. de Clercq, The expectation of the second Coming of Christ in Tertullian, in: Studia Patristica, Bd. 11, Berlin 1972, 146-151. 
sigillati per la redenzione finale al momento della seconda venuta del Signore. Grazie al sacramento del battesimo, il neofita partecipa già alla risurrezione, dal momento che è morto, sepolto e risorto con Cristo, per fruire fin da ora della vita dello spirito ${ }^{8}$. Nella celebrazione eucaristica il popolo cristiano partecipa al banchetto escatologico annunziato dal profeta Isaia (Is 25, 10), durante il quale il corpo e il sangue del Signore glorioso vengono ricevuti già sulla terra. Insomma, il premio eterno dell'al di là viene considerato già trasmesso, come primizia, attraverso la partecipazione ai sacramenti. La combinazione, dunque, dell'esperienza escatologica con i primi concetti teologici permise ai tempi post-apostolici di conservare intatta la polarità tra già e non ancora caratteristica del Nuovo Testamento.

Certamente, la complessa concettualità che accompagna il problema dell'escatologia - che fa riferimento interno ai temi del ritorno di Cristo, dello stato post-mortem, della fine del mondo; e riferimento esterno alla problematica della giustizia di Dio, della grazia e dei sacramenti - si formò progressivamente nella riflessione ecclesiale, a partire già dal secondo secolo. Di seguito ne verranno evidenziate le fasi di sviluppo.

2. Le prime tematizzazioni dell'escatologia. Nel II secolo vengono focalizzati i temi della parusia, della risurrezione dei morti, del giudizio universale, della fine violenta dell'universo ${ }^{9}$. Quanto alla parusia, la si avverte come prossima e accompagnata da segni. Sant'Ignazio di Antiochia e lo Pseudo-Barnaba, ad esempio, dicono che viviamo negli ultimi tempi ${ }^{10}$. La $\Delta \iota \delta \alpha \chi \eta$ insegna che, anche se il momento della venuta di Cristo è sconosciuto, il Signore sarà preceduto dall'Anticristo ${ }^{11}$. Erma sostiene che la torre che simbolicamente raffigura la Chiesa è quasi compiuta ${ }^{12}$. Lo Pseudo-Barnaba sostiene che la creazione del mondo in sei giorni rappresenta seimila anni, dato che per la Bibbia un giorno del Signore è come mille anni. Il cosmo, perciò, durerà seimila anni. Ora, dato che Dio riposò nel settimo giorno, egli apparirà all'inizio del settimo millennio:

${ }^{8}$ Cf. ad es. Cyrillus Hierosolymitanus, Catechesis 20, 5.

${ }^{9}$ Per quanto riguarda l'escatologia del II secolo, cf. J.N.D. Kelly, Il pensiero cristiano delle origini, Bologna 1972, 562-565; A. Fernández, La escatología en los escritos de los Padres Apostólicos, in: „Burgense” 20(1979) 9-55; V. Grossi, Lineamenti di antropologia patristica, Roma 1983, 122-125.

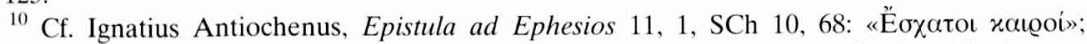

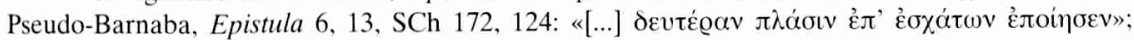

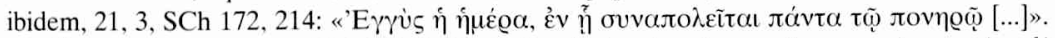

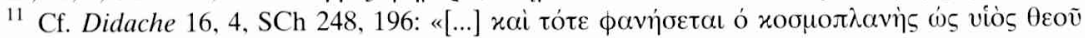
[...]». Cf. anche H.R. Seeliger, Erwägungen zu Hintergrund und Zweck des apokalyptischen Schlusskapitels der «Didache» [= Studia Patristica, 19], Louvain 1989, 185-192; F. Sbaffoni (ed.), Testi sull'Anticristo. Secoli I-II [= Biblioteca Patristica, 20], Firenze 1992.

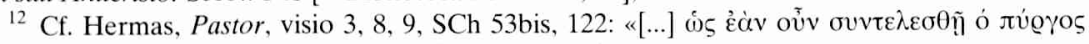

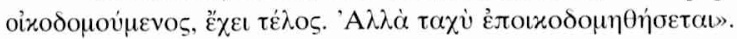


detronizzerà l'Ingiusto, giudicherà i malvagi e trasformerà tutto l'universo ${ }^{13}$. Ciò nonostante, il momento preciso di tutto ciò rimane sconosciuto ${ }^{14}$.

Quanto alla risurrezione dei morti, appare subito chiaro il suo legame con l'evento critico e l'universalità dei suoi effetti. Qualche opinione isolata interpretò la risurrezione come esclusiva dei giusti, ad esempio la $\Delta \iota \delta \alpha \chi \eta \dot{~ p r e c i s a ~}$ che «non tutti però» risorgeranno ${ }^{15}$. Ciò nonostante, in generale si insegnava che sarebbero risuscitati tutti, sia i buoni che i cattivi. E così lo Pseudo-Barnaba si appella a san Paolo, secondo il quale Cristo è risorto per annullare la morte e per darci la prova della nostra risurrezione ${ }^{16}$. Sant'Ignazio di Antiochia presenta la risurrezione del Signore come l'archetipo della nostra risurrezione ${ }^{17}$. Si insiste inoltre - specialmente contro gli errori degli gnostici e, in seno ad essi, i doceti - sulla necessità che questa nostra risurrezione si compia nella nostra medesima carne, affinché possiamo ottenere la giusta ed esatta contropartita del nostro comportamento ${ }^{18}$. San Policarpo di Smirne, volendo combattere i suddetti eretici, afferma che «chi nega la risurrezione e il giudizio è il primogenito di Satana» ${ }^{19}$.

San Clemente di Roma è il primo a fornire delle argomentazioni a favore della risurrezione: l'ordine dell'universo fornisce l'analogia del passaggio dalla notte al giorno e del mutamento di un seme in una pianta; la mitologia presenta l'analogia della fenice ${ }^{20}$. La risurrezione, però, è garantita dall'onnipotenza di Dio ed è preannunziata nella Bibbia (ad es.: Sal 3, 6; 23, 4; 28, 7; Giobbe 19, 26$)^{21}$.

La terza componente del pensiero escatologico del II secolo, cioè il tema del giudizio universale, trova espressione nell'idea del «venire a giudicare

${ }^{13}$ Cf. Pseudo-Barnaba, Epistula 15.

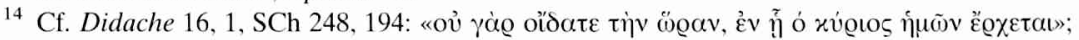

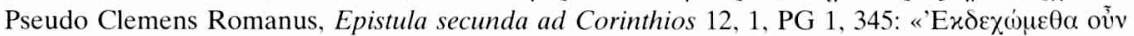

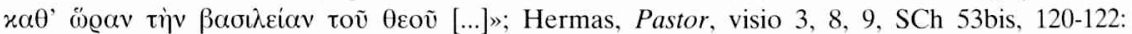

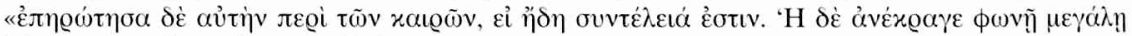

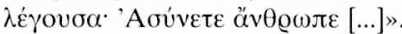

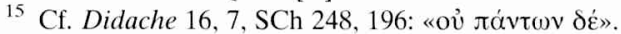

${ }^{16}$ Cf. Pseudo Barnaba, Epistula 5, 6.

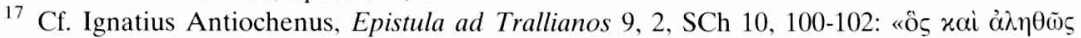

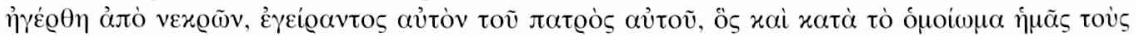

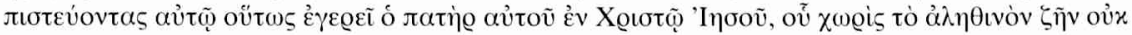

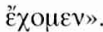

18 Cf. Clemens Romanus, Epistula ad Corinthios 24-26; Pseudo Barnaba, Epistula 21, 1; Pseudo Clemens Romanus, Epistula secunda ad Corinthios 9, 1-4.

${ }^{19}$ Polycarpus Smyrnaeus, Epistula ad Philippenses 7, 1, SCh 10, 186: «[...] $\left.\lambda \dot{\varepsilon} \gamma \eta\right\rceil \eta$

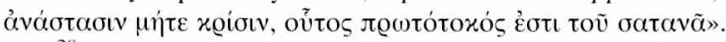

20 A proposito dell'uso della fenice, cf. P. Warsiński, Locus amoenus Christi et Phoenicis. Ze studiów nad wizerunkiem feniksa w literaturze i sztuce średniowiecznej, VoxP 11-12 (1991-1992) z. 20-23, 125-137; H. Wójtowicz, Feniks w literaturze wczesnochrześcijańskiej, VoxP 4(1984) z. 6-7, 376-384.

${ }^{21}$ Cf. Clemens Romanus, Epistula ad Corinthios 24-26. 
i vivi e i morti» ${ }^{22}$, che sottolinea l'unicità del giudizio divino alla fine dei tempi, per i vivi e per i morti, proclamazione che pare escludere il giudizio individuale subito dopo la morte che, presente in rarissimi autori patristici ${ }^{23}$, si affermerà nel medioevo latino. Inoltre, in generale il giudizio viene presentato come futuro e universale: il mondo presente perirà sciogliendosi violentemente nel sangue e nel fuoco ${ }^{24}$ (l'universo, infatti, dovrà essere trasformato per essere adatto agli elet $\mathrm{ti}^{25}$ ); i cattivi saranno distrutti e periranno in eterno ${ }^{26}$; i giusti, resi manifesti nella venuta del Regno di $\mathrm{Dio}^{27}$, vivranno incorrotti in eterno ${ }^{28}$.

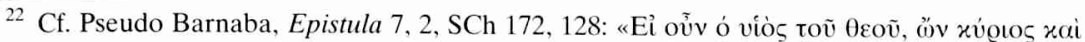

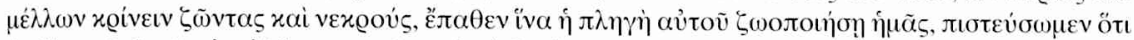

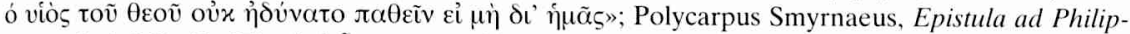

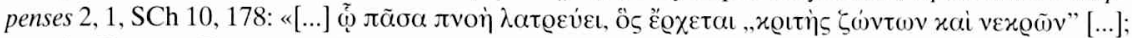

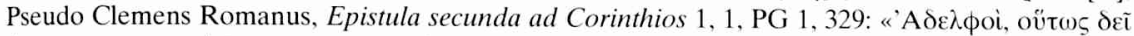

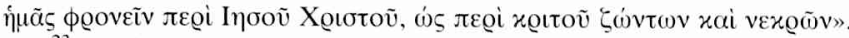

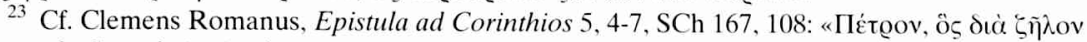

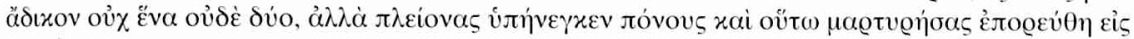

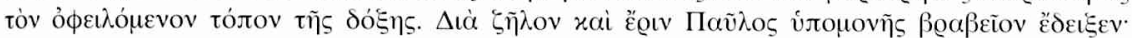

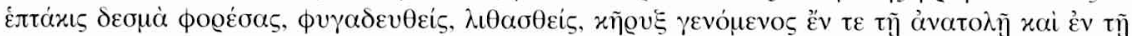

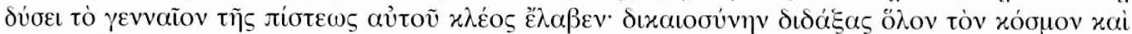

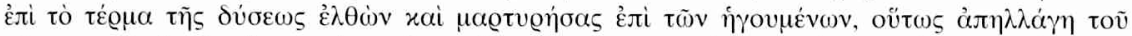

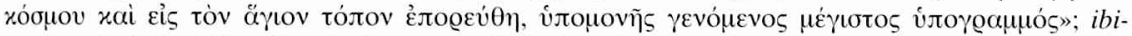

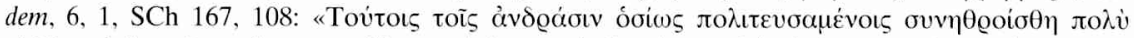

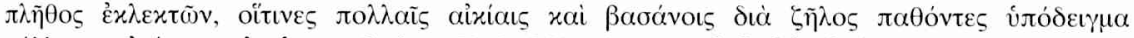

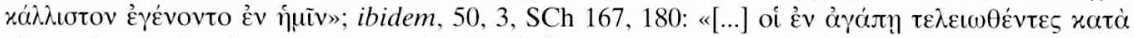

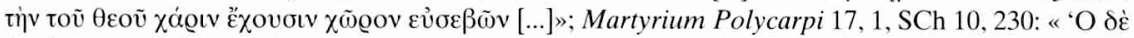

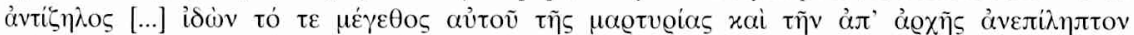

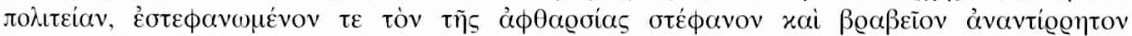

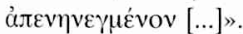

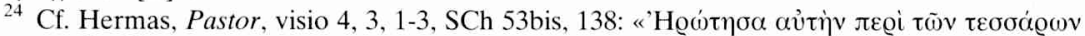

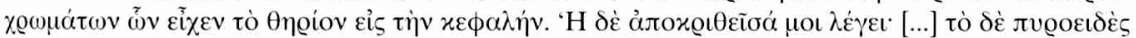

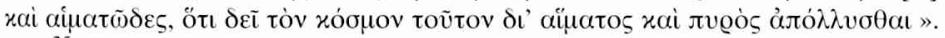

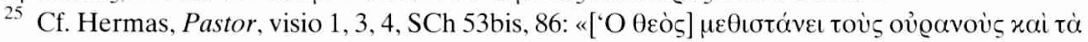

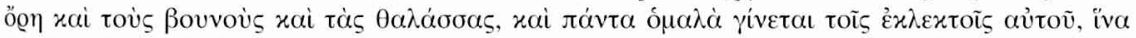

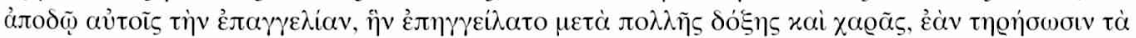

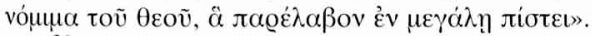

${ }^{26}$ Cf. Pseudo Clemens Romanus, Epistula secunda ad Corinthios 17, 7; Pseudo Barnaba,

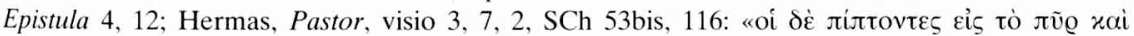

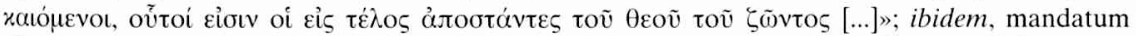

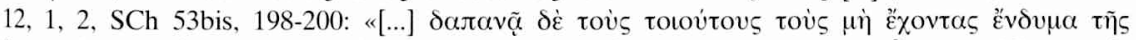

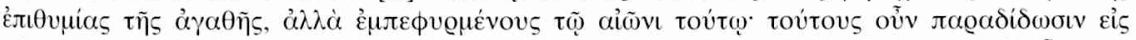

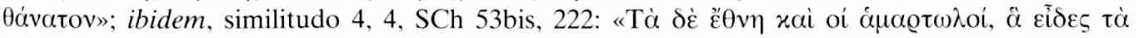

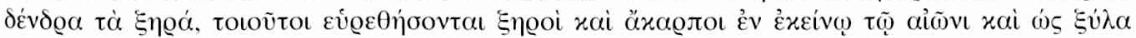

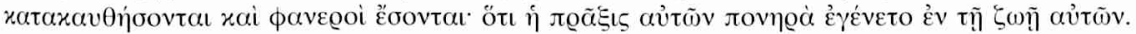

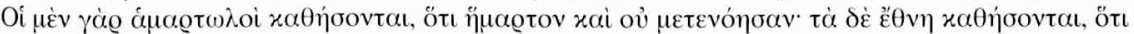

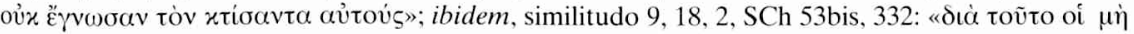

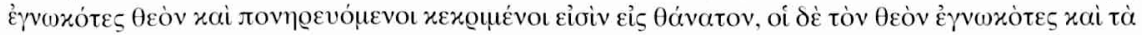


3. Lo sviluppo del dogma. Lo scontro con il paganesimo e il giudaismo contribuì ad un ulteriore sviluppo dell'escatologia cristiana andando a costituire le fondamenta del dogma ${ }^{29}$. Nei secoli II e III, infatti, la dottrina escatologica si trovò coinvolta in due correnti dottrinali e richiese pronunciamenti espliciti per una corretta interpretazione della parusia. Si tratta anzitutto della gnosi, che parlava di una semplice ascesa dell'anima per ritornare a Dio, e che fu immediatamente ricusata. In secondo luogo del millenarismo (detto diversamente «chiliasmo»), che, a differenza della gnosi, non fu un'eresia, bensì un'opinione teologica molto diffusa tra i cristiani e condivisa anche dai Padri di quell'epoca.

Il millenarismo, nato, come sembra, negli ambienti asiatici, avrà ben vaste propaggini ${ }^{30}$. Esso procede da una duplice sorgente sotto forme molto diversificate: la prima è l'Apocalisse che parla del regno di mille anni, inaugurato dalla prima risurrezione (dei giusti), prima della risurrezione universale e del giudizio finale; la seconda è un'assimilazione di questo schema della storia ultima della Chiesa allo schema della storia del Cristo nella sua estrema condizione sulla terra. Secondo tale opinione, il Signore sarebbe tornato sulla

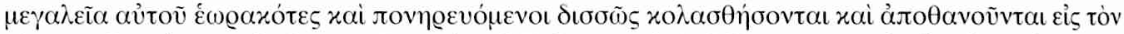

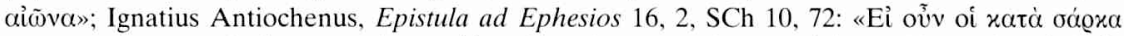

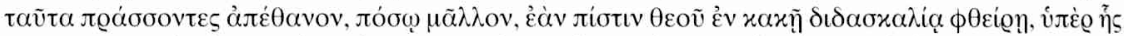

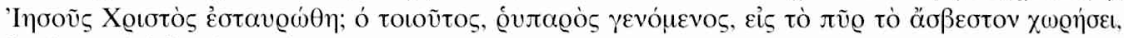

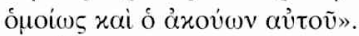

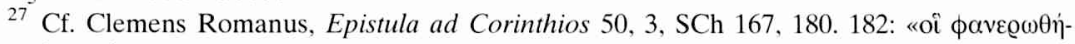

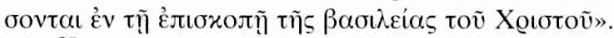

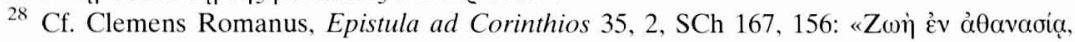

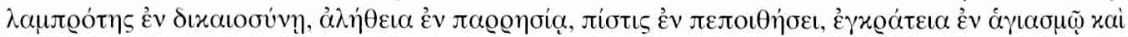

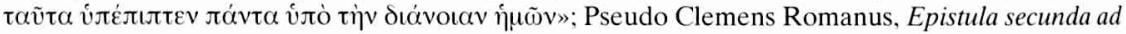

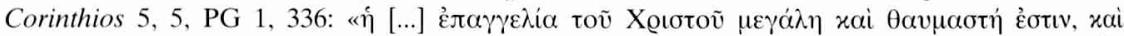

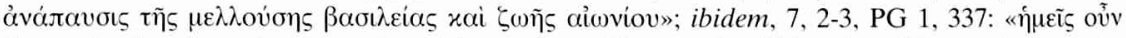

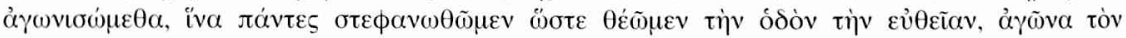

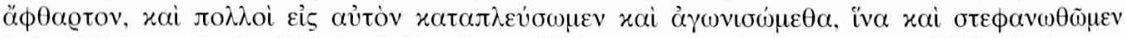
[...]»; ibidem, 11, 5, PG 1, 345: «ஸ̋

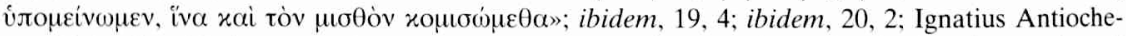

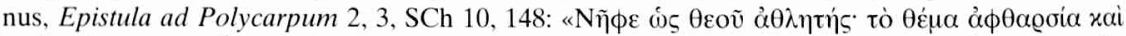

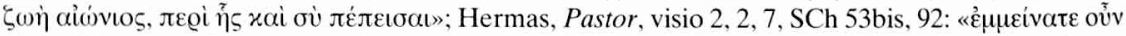

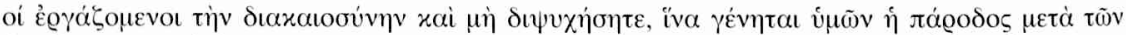

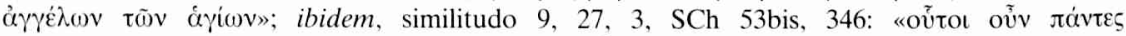

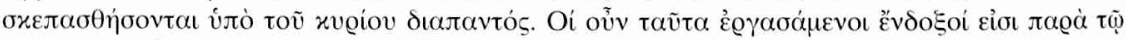

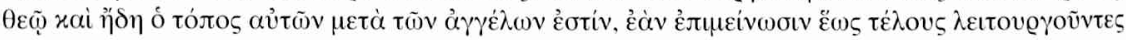
$\tau \tilde{\omega} x$ xui $\omega »$.

${ }^{29}$ Per quanto riguarda questo tema, cf. J.N.D. Kelly, Il pensiero cristiano delle origini, Bologna 1972, 566-571.

${ }^{30}$ Per quanto riguarda il millenarismo, cf. M. Simonetti, Il millenarismo in Oriente da Origene a Metodio, in: Corona Gratiarum (Miscellanea E. Dekkers), I, Brugges 1975, 37-58; L. Gry, Le millénarisme dans ses origines et son developpement, Paris 1904; Il millenarismo cristiano e i suoi fondamenti scritturistici $=$,Annali di storia dell' esegesi” 15(1998) nr 1, pp. 280. 
terra per mille anni per regnare con i giusti. Così si esprime san Giustino, in polemica con i Giudei, cercando argomenti scritturistici per provare che il Messia deve venire due volte; a suo parere, la Bibbia presenta la sua venuta in due modi diversi - nell'umiliazione e nell'abbassamento, ma anche in gloria, maestà e potenza (cf. Is 53, 8-12; Ez 7-8; Dn 7, 9-28; Za 10-12; Sal 72, 1-20; Sal $110,1-7)$. Quell'ultima venuta non si è ancora realizzata ${ }^{31}$. Essa si compirà a Gerusalemme dove sarà riconosciuto dai Giudei come Messia e regnerà con i suoi fedeli per mille anni ${ }^{32}$. Il millenarismo presentava il millenario regno terrestre di Cristo in modo idilliaco: i cristiani, insieme ai giusti dell'Antico Testamento, godranno perfetta felicità spirituale con Cristo assieme al benessere materiale . $^{33}$.

Per quanto concerne la risurrezione, gli apologisti ne cercano la comprensibilità razionale. San Giustino, ad esempio, richiama l'immagine dello sperma umano che diventa un corpo completo ${ }^{34}$. Atenagora di Atene ragiona nel seguente modo: l'essere umano, essendo composto di corpo e di anima, non può

${ }^{31}$ Cf. Iustinus, Prima Apologia 50-52; idem, Dialogus cum Tryphone 14, 31-32, 34; G. Pani, Il millenarismo: Papia, Giustino e Ireno, in: Il millenarismo cristiano, pp. 53-84.

32 Cf. Iustinus, Dialogus cum Tryphone 80, 5, in: E.J. Goodspeed (ed.), Die ältesten Apologeten, Göttingen 1984 (rist.), 191 (il testo è stato ripubblicato in: C. Nardi [ed.], Il millenarismo.

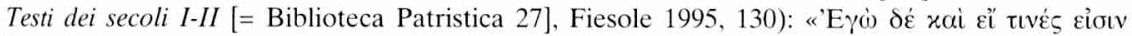

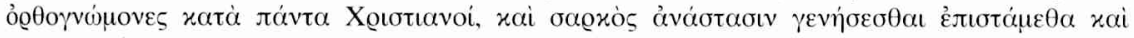

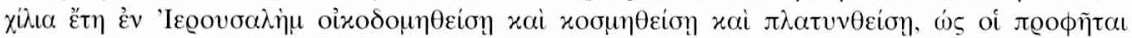

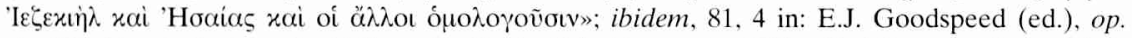

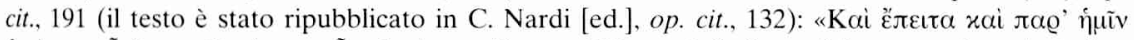

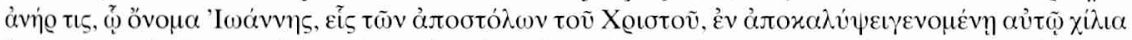

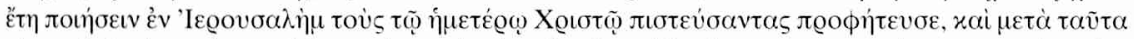

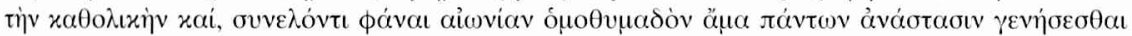
xai xoiøıv»; Tertullianus, Adversus Marcionem III 24, 3, SCh 399, 204 (il testo è stato ripubblicato in: C. Nardi [ed.], op. cit., 230, 232): «Nam et contitemur in terra nobis regnum promissum, sed ante caelum, sed alio statu, utpote post resurrectionem in mille annos in civitate divini operis Hierusalem caelo delata, quam et apostolus matrem nostram sursum designat; et politeuma nostrum, id est municipatum, in caelis esse pronuntians, alicui utique caelesti civitati eum deputat». Cf. anche Iustinus, Dialogus cum Tryphone 40, 4-5; 51, 2; 80, 1-2; 81, 1-4; 113, 4-5; 119, 5; 139, 4-5.

33 Cf. Iustinus, Dialogus cum Tryphone 80; Eusebius Caesariensis, Historia ecclesiastica III 28 , 2; VII 25, 2 in cui si descrive la teoria di Cerinto che addirittura parlava diffusamente delle gioie sensuali degli eletti; Irenaeus Lugdunensis, Adversus haereses V 33, 3; Tertullianus, Adversus Marcionem III 24; IV 39. Per quanto riguarda sant'Ippolito di Roma, egli professa il millenarismo nel suo commento al libro di Daniele e nel De Christo et Antichristo. Dal momento, però, che nella comunità di Roma il millenarismo trovò un'opposizione sempre crescente, il cui più noto rappresentante fu il sacerdote Ciao, Ippolito abbandonò questa dottrina e affermò che i mille anni di cui parla l'Apocalisse 22, 5 non devono essere interpretati letteralmente, bensì simbolicamente, in riferimento alla grandezza e alla bellezza del Regno di Dio (cf. Hippolytus Romanus, Capita contra Caium CCS I 2, 246 s.).

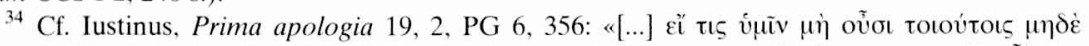

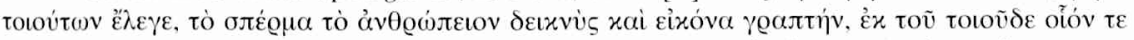

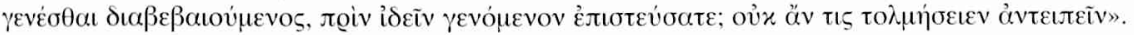


raggiungere in questa vita lo scopo per cui Iddio lo ha creato - cioè la vita eterna $^{35}$; pertanto è necessaria un'altra vita ove il corpo e l'anima vivranno eternamente uniti e in armonia ${ }^{36}$. Per quanto riguarda il giudizio finale, gli apologisti attingono paralleli dalla mitologia pagana ${ }^{37}$. In generale, essi pensano a un giudizio universale al momento della seconda venuta di Cristo. Ciò nonostante, sembra che san Giustino ammetta anche un giustizio particolare al momento della morte: le anime dei buoni andranno in un luogo più ameno in attesa del giudizio finale, mentre quelle dei cattivi in un luogo meno confortevole ${ }^{38}$.

I teologi immediatamente successivi agli apologisti, dovendo contrastare lo gnosticismo - secondo cui dopo la morte l'anima va immediatamente nel cielo -, mantennero il tradizionale insegnamento escatologico accentuandone due aspetti: il fatto che la resurrezione coinvolgerà anche la carne, e il fatto che prima del giudizio finale le anime resteranno in attesa, in un luogo non ancora glorioso. Fra questi padri, sant'Ireneo afferma che la salvezza concerne l'uomo intero $^{39}$ : conviene che il corpo, il quale aveva cooperato con l'anima nel bene, sia ad essa unito nel premio ${ }^{40}$; e ricorda che il colloquio di Cristo con i sadducei presuppone la risurrezione del $\operatorname{corpo}^{41}$; afferma anche che se il Signore ha assunto la carne materiale è evidente che essa è salvata ${ }^{42}$.

35 Cf. Athenagoras, De resurrectione mortuorum 12.

${ }^{36} \mathrm{Cf}$. Athenagoras, De resurrectione mortuorum 18-25. Per quanto riguarda la risurrezione dei morti Atenagora, cf. ad es. R. Jędrzejewski, Bóg a zmartwychwstanie ciał $w$ filozoficznoteologicznej myśli Atenagorasa z Aten, ,VoxP” 13-15(1993-1995) z. 24-29, 315-323.

${ }^{37}$ Cf. Iustinus, Prima apologia 8, 4; Theophilus, Ad Autolycum II 36-38.

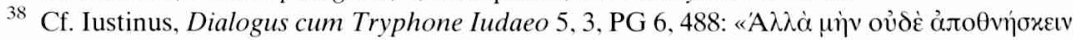

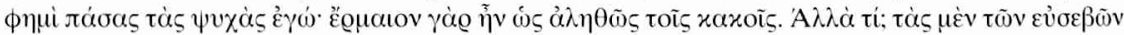

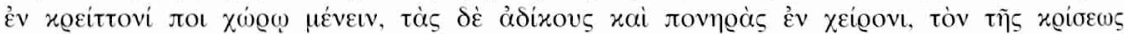

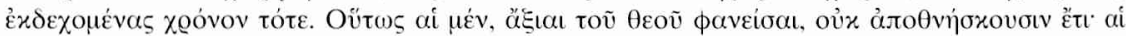

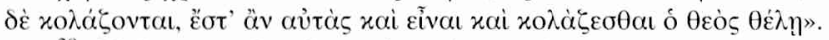

39 Cf. Irenaeus Lugdunensis, Adversus haereses V 2, 2 s.; V 20, 1. Per quanto riguarda l'escatologia di sant'Ireneo, cf. C. Masson, L'évangile éternel de l'Apocalypse (14, 6-7) [= Recueil K. Barth], Neuchâtel 1946, 63-67; A. Fischer, Studien zum Todesgedanken in der alten Kirche, München 1954; G. Lazzati, Sviluppi della letteratura sui martiri nei primi quattro secoli, Torino 1956; C. Masson, Immortalité de l'âme ou résurrection des morts?, „Revue de théologie et philosophie” 8(1958) 250-267; C. Tibiletti, S. Ireneo e l'escatologia nel „De Testimonio animae” di Tertulliano, „Atti dell'Accademia delle Scienze" (Torino) 94(1959) 1-41; P. Siniscalco, Apokatastasis e apokathisthemi nella tradizione della Grande Chiesa fino ad Ireneo, in: Studia Patristica, Bd. 3, Berlin 1961, 380-396; W.C. van Unnik, Der Ausdruck «in den letzten Zeit» bei Irenäus, in: Neotestamentica et Patristica (Festschrift O. Cullmann), Leiden 1962, 292-304; S. Prete, Escatologia e parenesi negli scrittori latini, Bologna 1965; M. Muccioli, Le esequie cristiane nella Chiesa dei primi tre secoli, Bologna 1969; H.I. Marrou, La théologie de l'histoire dans la gnose valentinienne, in: Origini dello gnosticismo, Leiden 1970, 215-225; V. Loi, La tipologia dell'agnello pasquale e l'attesa escatologica in età patristica, „Salesianum” 33(1971) 187-204; V. Grossi, Lineamenti di antropologia patristica, Roma 1983, 125-128.

${ }^{40}$ Cf. Irenaeus Lugdunensis, Adversus haereses II 29, 2.

41 Cf. Irenaeus Lugdunensis, Adversus haereses IV 5, 2. 
Tertulliano e Ippolito di Roma sono sulla stessa linea, ritenendo che basti la Scrittura per dimostrare la realtà della risurrezione della carne ${ }^{43}$ in quanto la carne è stata creata da Dio ed Egli non disprezza ciò che il Figlio ha assunto su di sé ${ }^{44}$. Inoltre, dato che l'anima e il corpo sono strettamente uniti, essi devono essere sottoposti insieme al giudizio ${ }^{45}$, e il rinnovarsi periodico dell'ordine naturale del cosmo, conferma la certezza della risurrezione $e^{46}$.

Per quanto riguarda la sorte delle anime durante l'attesa della risurrezione e del giudizio finale, Ireneo, sempre in opposizione agli gnostici, indica che lo stesso Cristo è disceso per tre giorni agli inferi. Perciò, anche le anime dei cristiani, imitando il loro maestro, dopo la morte staranno in un posto stabilito da Dio e vi resteranno sino alla risurrezione ${ }^{47}$. In seguito, al momento della

${ }^{42}$ Cf. Irenaeus Lugdunensis, Adversus haereses V 14.

${ }^{43}$ Cf. Tertullianus, De resurrectione mortuorum 18, 1, CCL 2, 942: «Hucusque praestructionibus egerim ad muniendos sensus omnium scripturarum, quae carnis recidiuatum pollicentur. Cui cum tot auctoritates iustorum patrociniorum procurent, honores dico substantiae ipsius, tum uires dei, tum exempla earum, tum rationes iudicii et necessitates ipsius, utique secundum praeiudicia tot auctoritatum scripturas intellegi oportebit, non secundum ingenia haereticorum, de sola incredulitate uenientia, quia incredibile habeatur restitui substantiam interitu subductam, non quia aut substantiae ipsi inemeribile sit aut deo inpossibile aut iudicio inhabile»; Hippolytus Romanus, De Antichristo 65, 1-3-66, 1-2, in: E. Norelli, Ippolito. L'Anticristo [= Biblioteca Patristica 10], Firenze

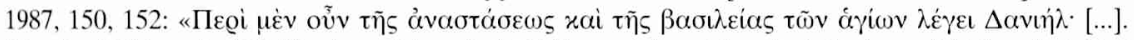

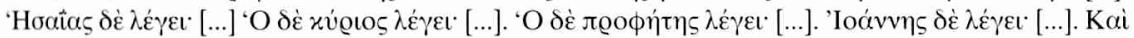

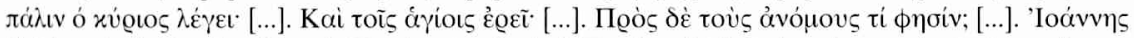

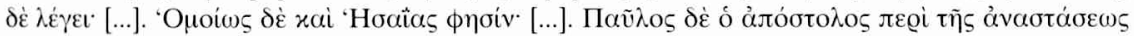

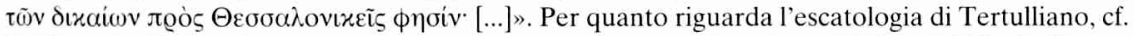
H. Finé, Die Terminologie der Jenseitsvorstellungen bei Tertullian, Bonn 1958; C. Tibiletti, Il senso escatologico di "pax» e «refrigerium» e un passo di Tertulliano (exh. cast. 1, 1), „Maia” 10(1958) 209-219; P. Siniscalco, I significati di «restituere» $e$ "restitutio» in Tertulliano, ,Atti dell'Accademia delle Scienze" (Torino) 93(1958-59) 386-436; C. Tibiletti, S. Ireneo e l'escatologia nel "De testimonio animae” di Tertulliano, „Atti dell'Accademia delle Scienze” (Torino) 94(1959) 1-41; S. Prete,

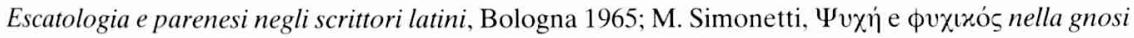
valentiniana, „Rivista di storia e letteratura religiosa” 2(1966) 1-47; P. Puente Santidrián, La terminologia de la resurreción en Tertuliano, „Burgense” 19(1978) 361-374; S. Vicastillo, Tertuliano y la muerte del hombre, Madrid 1980; K. Obrycki, Refrigerium u Tertuliana, PSP 29 (Warszawa 1983), 30-42; K. Obrycki, Los ztych po śmierci wedtug Tertuliana, VoxP 10(1990) z. 19, 599-608; P. Siniscalco, Argomentazioni escatologiche e pubblico in alcune opere di Tertulliano, in: De Tertullien aux Mozarabes (Mélanges J. Fontaine), I, Paris 1992, 393-402; W. Turek, Fiducia Christianorum resurrectio mortuorum. De connexione inter spem Christianam et resurrectionem carnis in Tertulliani operibus adversus haereses conscriptis [= Excerptum e Dissertatione Pontificiae Universitatis Studiorum Salesiana], Roma 1993; W. Turek, La speranza in Tertulliano [= Biblioteca di Scienze Religiose, 126], Roma 1997.

${ }^{44}$ Cf. Tertullianus, De resurrectione mortuorum 5-11.

${ }^{45}$ Cf. Tertullianus, De resurrectione mortuorum 14-16.

${ }^{46}$ Cf. Tertullianus, De resurrectione mortuorum 12.

${ }^{47}$ Per quanto riguarda la dottrina sulla discesa agli inferi nell'età patristica, cf. ad es. K.H. Schelkle, Die Petrusbriefe. Der Judasbriefe, Freiburg-Basel-Wien 1964² , 98-117; W.J. Dalton, Christ's Proclamation to the Spirits. A Study of 1 Peter 3, 18-4, 6, Roma 1965; J. Capmany, Discesa 
risurrezione finale, con il loro corpo vedranno perfettamente $\mathrm{Dio}^{48}$. Soltanto i martiri non dovranno attendere in questo luogo di attesa ${ }^{49}$. La stessa dottrina viene professata anche dagli altri teologi del tempo ${ }^{50}$.

4. Deificazione e risurrezione del cristiano secondo Origene. Origene interpretava il Regno di Dio come l'abitazione del Verbo o la semenza della verità seminata nell'anima ${ }^{51}$, o come la conoscenza di Dio e delle realtà celesti ${ }^{52}$, o come la dottrina del Verbo, insegnata da Gesù Cristo ${ }^{53}$. Il voṽ s purificato, che si alza sopra la materia in cerca di una visione di Dio eterna, è deificato dalla sua visione ${ }^{54}$. Dato che la vera gnosi si basa sull'unione tra colui che conosce e il suo oggetto, la conoscenza divina dei credenti culmina nella loro unione con $\mathrm{Dio}^{55}$.

di Gesù agli inferi, in: Enciclopedia della Bibbia, Torino 1969, 940-941; J. Daniélou, La teologia del giudeo-cristianesimo, Bologna 1974, 325. 334; U. Vanni, Lettere di Pietro, Giacomo, Giuda, Roma 1974, 59-60. 64-65; M. Simonetti, Praecursor ad inferos. Una nota sull'interpretazione patristica di Matteo 11, 3, „Augustinianum” 20(1980) 367-382; E. Peretto, Discesa agli inferi, DPAC I 981-991; H. Crouzel, L'Hadès et la Géhenne selon Origène, „Gregorianum” 59(1978) 291-331; H. Pietras, Kerygmatyczna treść formuty "Zstąit do piekiet» u pierwszych Ojców, in: F. Drączkowski J. Pałucki (edd.), Ewangelizacja w epoce patrystycznej, Lublin 1994, 103-123.

${ }^{48}$ Cf. Irenaeus Lugdunensis, Adversus haereses V 31, 1. Cf. anche H. Finé, Die Terminologie der Jenseitsvorstellungen bei Tertullian. Ein semasiologischer Beitrag zur Dogmengeschichte des Zwischenzustandes [= Theophaneia, 12], Bonn 1958, 36.

${ }^{49}$ Cf. Irenaeus Lugdunensis, Adversus haereses IV 33, 9.

${ }^{50}$ Cf. Tertullianus, De anima 55-58; idem, De testimonio animae 4, 1; 4, 5-6; 5, 4; Hippolytus Romanus, Contra Graecos (PG 10, 796-800). Cf. anche C. Tibiletti, L'oltretomba in antiche epigrafi cristiane, in: Scritti sul mondo antico in memoria di F. Grosso, Roma 1981, 605-620; idem, S. Ireneo e l'escatologia del "De Testimonio animae”, „Atti dell'Accademia delle Scienze di Torino" 94(19591060) 290-330.

51 Cf. Origenes, Commentarii in Evangelium Ioannis 19, 12, 78. Per quanto riguarda l'escatologia di Origene, cf. H. Cornelis, Les fondaments cosmologiques de l'éschatologie d'Origène, „Revue des Sciences Philosophiques et Théologiques” 43(1959) 32-81; J.N.D. Kelly, Il pensiero cristiano delle origini, Bologna 1972, 572-577; M. Simonetti, Il millenarismo in Oriente da Origene a Metodio, in: Corona Gratiarum (Miscellanea E. Dekkers), I, Brugges 1975, 37-58; V. Grossi, Lineamenti di antropologia patristica, Roma 1983, 132-137; M. Maritano, L'argomentazione scritturistica di Origene contro i sostenitori della metensomatosi, in: Origeniana sexta, Leuven 1995, 251-276.

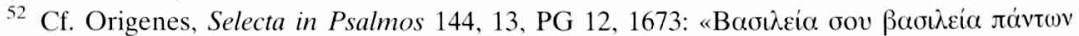

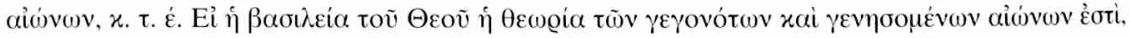

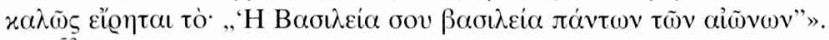

${ }^{53}$ Cf. Origenes, Commentarium in evangelium Matthaei X 14, PG 13, 869: «Oüt

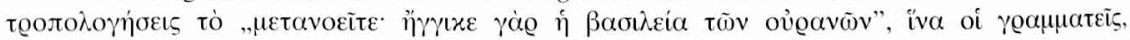

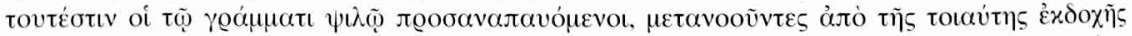

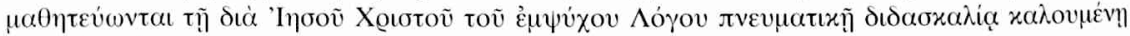

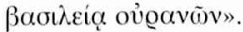

${ }^{54}$ Cf. Origenes, In Iohannem 43, 37, 338.

${ }^{55}$ Cf. Origenes, In Iohannem 9, 4, 23. 
La risurrezione è collegata alla dottrina della deificazione: a difesa del dogma cristiano, Origene si schierò sia contro il semplice letteralismo sia contro lo spiritualismo degli eterodossi (gli gnostici e i manichei). Egli comin-

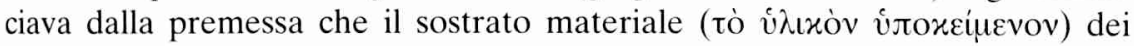
corpi si trova in uno stato continuamente fluido: le sue qualità cambiano sempre. Ciò nonostante, tutti i corpi possiedono una immutata forma caratte-

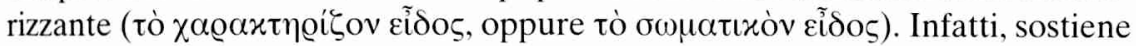
Origene, dall'infanzia sino alla canizie, il corpo umano rimane sempre lo stesso, nonostante il suo totale mutamento fisico ${ }^{56}$. Per questa ragione, il corpo dei risuscitati sarà del tutto uguale al corpo che avevano durante la vita terrena, dal

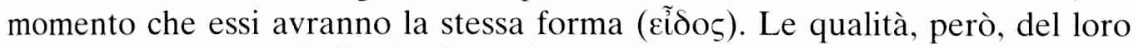
sostrato materiale ( al regno celeste. Il corpo che serve l'anima durante la vita terrestre è psichico, quando, invece, l'anima sarà unita a Dio, anche il corpo diventerà spirituale $\mathrm{e}^{57}$.

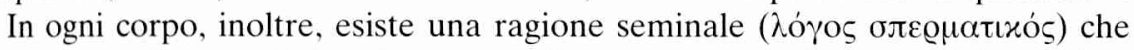
permette al corpo di risuscitare, come il seme gettato nel terreno si ricostruisce in uno stelo di grano ${ }^{58}$.

Per quanto riguarda il giudizio finale, il grande Alessandrino sembra affermare che subito dopo la morte avviene una separazione transitoria fra le anime degli uomini. Esse passano ad uno stadio intermedio che serve come una scuola di prova; solo alla fine del mondo si compirà il giudizio propriamente detto ${ }^{59}$, e avverrà la separazione definitiva tra i buoni e gli empi ${ }^{60}$. Origene, però, fornisce una interpretazione spirituale del giudizio finale ${ }^{61}$ : si tratta della manifestazione della divinità del Signore a tutti gli uomini; il Signore si farà conoscere in ogni luogo e gli uomini si presenteranno al suo trono e si vedranno nella loro realtà. In tale ottica, non c'è più posto per il millenarismo. Anzi, esso viene criticato da Origene ${ }^{62}$.

L'Alessandrino, inoltre, essendo convinto che il regno dei giusti è la contemplazione della verità di Dio, interpreta le pene dei dannati in termini spirituali $^{63}$ : la pena degli empi consiste nella loro sofferenza interiore. Inoltre, le pene dei dannati avranno un giorno fine ${ }^{64}$. Il loro castigo ha un fine

\footnotetext{
${ }^{56}$ Cf. Origenes, Selecta in Psalmos 1, 5.

57 Cf. Origenes, De principiis III 6, 6; idem, Contra Celsum III 41 s.; IV 56 s.

58 Cf. Origenes, De principiis II 10, 3; idem, Contra Celsum V 18 s.; VII 32; VIII 49.

59 Cf. Origenes, De principiis II 11, 6. Cf. anche C. Tibiletti, Le anime dopo la morte: stato intermedio o visione di Dio? Dalla Patristica al sec. XIV, „Augustinianum” 18(1988) 631-669.

${ }^{60}$ Cf. Origenes, De principiis II 9, 8; idem, Contra Celsum IV 9.

${ }^{61}$ Cf. Origenes, Commentarium in evangelium Matthaei XII 30.

${ }^{62}$ Cf. Origenes, De principiis II 11, 2; idem, Commentarium in evangelium Matthaei XVII 35;
} Idem, In Canticum canticorum, prologus; idem, Selecta in Psalmos 4, 6.

${ }^{63}$ Cf. Origenes, De principiis II 10, 14.

${ }^{64}$ Cf. Origenes, Contra Celsum III 79; 6, 26; idem, In Ieremiam homilia 19, 4. 
terapeutico e avrà termine quando il peccatore cesserà di peccare ${ }^{65}$. Si tratta della sua dottrina dell'apocatastasi. Anche san Paolo (cf. 1 Cor 15, 25) ha detto che, alla fine, tutte le realtà saranno sottoposte a Dio, il quale - come in principio - sarà tutto in tutti. Ciò, tuttavia, non avverrà - per quanto riguarda gli esseri razionali - per necessità, ma tramite la persuasione ${ }^{66}$. Sembra che anche il Diavolo sarà partecipe della restaurazione finale. Bisogna, però, dire che, per quanto riguarda questo aspetto, si ha la testimonianza contraria di Rufino di Aquileia ${ }^{67}$ il quale riporta che allorquando Origene veniva interrogato in proposito, non riconosceva come proprio insegnamento tale dottrina. Ciò nonostante, quest'opinione rientrava comunque nel suo sistema, giacché legata all'assolutezza del potere di Dio.

5. La risurrezione dei morti nel periodo successivo. Per i teologi successivi al grande Origene, sia greci che latini, il dogma tradizionale non presentava alcuna difficoltà, data l'onnipotenza di Dio. Ciò nonostante, le accentuazioni dottrinali diverse consentono di individuare due correnti: 1) coloro che affermarono che il pensiero di Origene nega una risurrezione reale; 2 ) coloro che imitando l'Alessandrino - cercarono di comprendere la risurrezione in modo più profondo, scartando, tuttavia, tutto ciò che nell'insegnamento di Origene era eccessivo ${ }^{68}$.

Tra i Padri Orientali che si opposero ad Origene ricordiamo Eustazio di Antiochia ed Epifanio di Salamina ${ }^{69}$, entrambi al seguito della critica a Origene mossa da Metodio di Olimpo (†311 ca.). Costui sosteneva che la teoria secondo cui l'anima aveva peccato nel suo stato precedente l'incarnazione era sbagliata e, inoltre, respingeva la teoria origeniana secondo la quale l'elemento che rimane dopo la risurrezione è la forma corporea e non il corpo stesso $^{70}$. Difatti, secondo Metodio, questa forma è semplicemente un modello

${ }^{65} \mathrm{Cf}$. ad es. In Ezechielem homilia 1, 2.

${ }^{66}$ Cf. Origenes, De principiis III 5, 7 s.; ibidem, III 6, 6; I 6, 4.

${ }^{67}$ Cf. Rufinus, De adulteratione librorum Origenis 7, CCL 20, 11: «De adulteratione uel corruptione librorum suorum ex libro epistularum Origenis quarto [epistulae scriptae ad quosdam caros suos Alexandriam] ,quidam eorum qui libenter habent criminari proximos suos, adscribunt nobis et doctrinae nostrae crimen blasphemiae, quod a nobis numquam audierunt. De quo ipsi uiderint, nolentes obseruare mandatum illud quod dicit quia: maledicti regnum Dei non possidebunt, dicentes me patrem malitiae ac perditionis et eorum qui de regno Dei eiciuntur, id est diabolum, dicere esse saluandum: quod ne aliquis quidem mente motus et manifeste insaniens dicere potest. Sed nihil mirum mihi uidetur, si adulteretur doctrina mea ab inimicis et tali adulterio corrumpatur, quali adulterio corrupta est epistula Pauli apostoli [...]"».

${ }^{68}$ Per quanto riguarda la problematica trattata in questo paragrafo, cf. J.N.D. Kelly, $I l$ pensiero cristiano delle origini, Bologna 1972, 578-583.

${ }^{69}$ Cf. Eusthatius, De engastrimytho adversum Origenem 22, PG 18, 660; Epiphanius, Panarion 64, 63-68; idem, Ancoratus 87-92.

${ }^{70}$ Cf. Methodius Olympius, De resurrectione 29-33. 
totalmente esterno al corpo, come il tubo per cui passa l'acqua ${ }^{71}$. Inoltre, Cristo è risuscitato nel medesimo corpo che aveva sulla croce ${ }^{72}$. Un altro Padre che si oppose ad Origene fu san Girolamo ( $†$ 419). Fino al 394 egli era stato un fedele discepolo di lui, più tardi, però, cambiò diametralmente posizione, accettando l'identità del corpo fisico dopo la risurrezione con il corpo terrestre ${ }^{73}$.

E che cosa accade se il corpo viene distrutto nella decomposizione dei corpi dopo la morte, o se viene divorato da animali o consumato dal fuoco? San Cirillo di Gerusalemme risponde a tale obiezione che dobbiamo affidare ciò all'onnipotenza di Dio $^{74}$. Ciò nonostante, comprende la risurrezione come un mutamento in un certo senso spirituale: cioè la risurrezione di questo medesimo corpo, ma non esattamente così come è stato durante la vita terrestre, i corpi dei buoni, infatti, avranno delle qualità soprannaturali e celesti, mentre i corpi dei cattivi bruceranno per tutta l'eternità ${ }^{75}$. Anche Didimo il Cieco insegnava che il corpo dopo la risurrezione sarà celeste: il corpo terrestre sarà assorbito e avrà qualità soprannaturali ${ }^{76}$.

San Gregorio di Nissa, sulla scia di Origene, distingueva fra i componenti naturali del corpo (che mutano sempre, essendo di continuo creati e distrutti)

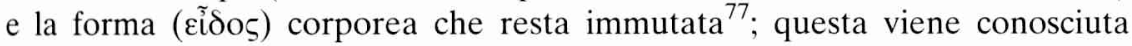
dall'anima e lascia sull'anima la sua impronta. Quindi sarà l'anima ad attirare a sé durante la risurrezione tutti gli elementi di cui avrà bisogno. Per il Nisseno, il corpo glorioso non sarà soggetto alle conseguenze del peccato, ma sarà elevato a uno stato impassibile e spirituale, dato che l'uomo verrà

${ }^{71}$ Cf. Methodius Olympius, De resurrectione 3, 3.

72 Cf. Methodius Olympius, De resurrectione 3, 12-14.

${ }^{73}$ Cf. ad es. Hieronymus, Contra Iohannem Hierosolymitanum 33, PL 23, 401-402: «Veniet hora, in qua omnes qui in monumentis sunt, audient vocem Filii Dei, et procedent. Audient auribus, procedent pedibus. Hoc et Lazarus ante iam fecerat. Procedent autem de monumentis, id est, qui monumentis illati fuerant, uenient mortui, et resurgent de sepulcris suis. [...]. Et exibunt de sepulcris suis, ueluti hinnuli de uinculis soluti. Gaudebit cor eorum, et ossa eorum sicut sol orientur; veniet omnis caro in conspectu Domini, et mandabit piscibus maris, et eructabunt ossa quae comederant, et faciet compagem ad compagem, et os ad os; et qui in terrae pulvere dormierunt, resurgent; alii in vitam aeternam, alii in opprobrium et confusionem aeternam». Per quanto riguarda l'escatologia di san Girolamo, cf. J.P. O'Connell, The Eschatology of Saint Jerome, Mundelein (Ill.) 1948.

${ }^{74}$ Cf. Cyrillus Hierosolymitanus, Catechesis $18,2 \mathrm{~s}$.

${ }^{75}$ Cf. Cyrillus Hierosolymitanus, Catechesis $18,18 \mathrm{s.}$

76 Cf. Didymus Alexandrinus, In II ad Corinthios 5, 1-2, PG 39, 1704.

77 Cf. Gregorius Nyssenus, De opificio hominis 27; idem, De anima et resurrectione, PG 46, 73-80. Cf. anche P. Evdokimov, La donna e la Salvezza del mondo, Milano 1980, 128; E. Peroli, Il Platonismo e l'antropologia filosofica di Gregorio di Nissa con particolare riferimento agli influssi di Platone, Plotino e Porfirio [= Platonismo e filosofia patristica. Studi e testi, 5], Milano 1993, 125-221. Sull'escatologia del Nisseno, cf. anche A. Le Boulluec, Corporéité ou individualité? La condition finale des ressuscités selon Grégoire de Nysse, „Augustinianum” 35(1995) 307-326. 
riportato alla condizione primitiva, perduta a causa della prevaricazione di Adamo $^{78}$.

Per quanto riguarda l'Occidente cristiano, sant'Ilario di Poitiers sosteneva che Dio ricostruirà la medesima materia, ma le darà bellezza degna dello stato soprannaturale ${ }^{79}$. Sant'Ambrogio insegnava che il corpo risuscitato sarà trasformato e spiritualizzato ${ }^{80}$, pur restando il medesimo corpo terreno ${ }^{81}$. Il corpo, però, sarà anche sottoposto, insieme all'anima, al giudizio finale ${ }^{82}$. Anche sant'Agostino prende posizione sulla problematica ${ }^{83}$, risolvendo la difficoltà che i corpi terreni possano essere risuscitati con l'onnipotenza divina, anche se

${ }^{78}$ Cf. Gregorius Nyssenus, De anima et resurrectione, PG 46, 148 s. Cf. anche P. Evdokimov, La donna e la Salvezza del mondo, Milano 1980, 128.

${ }^{79}$ Cf. Hilarius Pictaviensis, Tractatus super Psalmos 2, 41. Per quanto riguarda alcuni aspetti dell'escatologia di sant'Ilario, cf. J. Doignon, Hilaire de Poitiers face à la mystique origénienne de la purification par l'amour, ,Revue des Etudes Augustiniennes” 36(1990) 217-224; J. Doignon, "Haec Musa laetitiae est”. Un poétisme dans le registre eschatologique d'Hilaire de Poitiers, „Orpheus” $17(1996)$ 396-400.

${ }^{80}$ Cf. Ambrosius Mediolanensis, Explanatio Psalmorum XII 1, 51, 4, CSEL 65, 44: «Quid autem hoc euidentius, quod ait alibi: omnes quidem resurgemus, sed non omnes immutabimur? Immutabuntur enim iusti in incorruptionem manente corporis ueritate»; idem, Expositio Evangelii secundum Lucam X 169, CCL 14, 394: «Nam quod tangitur corpus est, quod palpatur corpus est; in corpore autem resurgimus; seminatur enim corpus animale, surgit corpus spiritale, sed illud subtilius, hoc crassius, utpote adhuc terrenae labis qualitate concretum». Per quanto riguarda alcuni aspetti dell'escatologia ambrosiana, cf. D. Doucet, L'époux des mes. Porphyre, Ambroise, Augustin: "De bono mortis» 14-20; "De ordine» I 8, 24, ,Revue des Etudes Augustiniennes” 41(1995) 231-252.

${ }^{81}$ Cf. Ambrosius Mediolanensis, De excessu fratris Satyri 2, 87, CSEL 73, 297: «Si terra renovatur et caelum, cur dubitemus hominem posse renovari, propter quem terra facta vel caelum est? Si praevaricator servatur ad poenam, cur iustus non perpetuatur ad gloriam? Si vermis non moritur peccatorum, quemadmodum interibit caro iustorum? Haec est enim resurrectio - sicut verbi ipsius sonus exprimitur - ut, quod cecidit, hoc resurgat, quod mortuum fuerit, revivescat».

82 Cf. Ambrosius Mediolanensis, De excessu fratris Satyri 2, 88, CSEL 73, 297: «Et haec est series et causa iustitiae, ut quoniam corporis animi que communis est actus, quia animus cogitavit, corpus effecit, utrumque in iudicium veniat, utrumque aut poenae dedatur aut gloriae reservetur. Nam propemodum absurdum videtur, ut, cum animi legem lex carnis inpugnet et mens plerumque, quod odit, hoc faciat, quando inhabitans in homine peccatum carnis operatur, animus subdatur iniuriae, alienae reus culpae, caro quiete potiatur, auctor aerumnae, et solus adteratur, qui non solus erravit, aut solus gloriam referat, qui non solus gloriae militavit».

83 Per quanto riguarda il pensiero escatologico di sant'Agostino, cf. E. Lewarter, Eschatologie und Weltgeschichte in der Gedankenwelt Augustins, ZKG 63(1934) 1-51; H.I. Marrou, Le dogme de la résurrection des corps et la théologie des valeurs humains selon l'enseignement de s. Augustin, „Revue des Etudes Augustiniennes” 12(1966) 111-136; B. Lohse, Zur Eschatologie des älteren Augustinus (De civ. Dei 20, 9), VigCh 21(1967) 221-240; V. Grossi, Lineamenti di antropologia patristica, Roma 1983, 137-139; J.K. Coyle, Augustine and apocalyptic. Thougts on the fall of Rome, the Book of Revelation, and the end of the world, „Florilegium” 9(1987) 1-34; J. Doignon, Autour d'un fragment du livre 3 du "De re publica" de Cicéron invoqué, au temps d'Augustin, par des Porphyriens contre la résurrection des corps, „Orpheus” 13(1992) 26-32; H. Kotila, Memoria mortuorum. Commemoration of the departed in Augustine [= Studia Ephemeridis Augustinia- 
distrutti in vari modi ${ }^{84}$, e accogliendo, dunque, che risorgerà la stessa identica carne che è stata sepolta ${ }^{85}$. Egli si sofferma anche sul grado di maturità del corpo e afferma che i bambini o i giovani avranno il corpo maturo delle persone adulte $^{86}$. I corpi dei dannati, poi, saranno incorruttibili, affinché possano essere puniti eternamente ${ }^{87}$. I corpi dei santi, per contro, saranno perfetti, senza nulla di ciò che è deforme o brutto ${ }^{88}$. Bisogna alla fine aggiungere che sant'Agostino presenta la risurrezione universale nell'ultimo giorno come un sicuro dogma della fede cattolica ${ }^{89}$.

num, 38], Roma 1992; D. Doucet, L'époux des mes. Porphyre, Ambroise, Augustin: "De bono mortis» 14-20; "De ordine» I 8, 24, , Revue des Etudes Augustiniennes” 41(1995) 231-252.

${ }^{84}$ Cf. Augustinus Hipponensis, De civitate Dei XXII 20, 1, CCL 48, 839: «Absit autem, ut ad resuscitanda corpora uitaeque reddenda non possit omnipotentia Creatoris omnia reuocare, quae uel bestiae uel ignis absumpsit, uel in puluerem cineremque conlapsum uel in umorem solutum uel in auras est exhalatum. Absit ut sinus ullus secretumque naturae ita recipiat aliquid subtractum sensibus nostris, ut omnium Creatoris aut cognitionem lateat aut effugiat potestatem».

${ }^{85}$ Cf. Augustinus Hipponensis, Sermo 264, 1, PL 38, 1212: «Tamen ne fraudemus eos qui esurientes veniunt, etsi breviter, non tacebimus huius rei sacramentum, quod Dominus noster Iesus Christus cum eo corpore, in quo resurrexit ascendit. Sane propter infirmitatem discipulorum suorum: non enim deerant etiam in illo numero, quos diabolus infidelitate tentaret, ita ut quidam discipulus eius in ipsa specie in qua noverat, non tamen magis fidem haberet viventibus membris, quam recentibus cicatricibus: ergo ad eorum confirmationem dignatus est post resurrectionem vivere cum illis quadraginta diebus integris, ab ipso die passionis suae usque in hodiernum diem, intrans et exiens, manducans et bibens, sicut dicit scriptura; confirmans hoc redditum esse oculis eorum post resurrectionem, quod ablatum erat per crucem».

86 Cf. Augustinus Hipponensis, Sermo 242, 4, PL 38, 1140: «Adhuc disputant, et quaerunt a nobis: parvuli qui moriuntur, parvuli resurrecturi sunt? An aetas erit plena reviviscentium, quorum erat parva morientium? Hoc quidem in scripturis definitum non invenimus. Incorruptibilia corpora et immortalia resurrectura promissa sunt. Sed si parva aetas redditur, si statura pusilla revocatur, numquid et propterea infirmitas revocatur? Si parvi erunt, numquid iacebunt, et ambulare non poterunt? Credibilius tamen accipitur et probabilius et rationabilius, plenas aetates resurrecturas, ut reddatur munere, quod accessurum erat tempore. Non enim credituri sumus etiam senectam resurrecturam anhelam et curvam. Postremo corruptionem tolle, et quod vis adde».

${ }^{87}$ Cf. Augustinus Hipponensis, Enchiridion ad Laurentium de fide, spe et caritate 23, 92, CCL 46, 98: «Quicumque uero ab illa perditionis massa, quae facta est per hominem primum, non liberantur per unum mediatorem Dei et hominum, resurgent quidem etiam ipsi, unusquisque cum sua carne, sed ut cum diabolo et eius angelis puniantur. Vtrum sane ipsi cum uitiis et deformitatibus suorum corporum resurgant, quaecumque in eis uitiosa et deformia membra gestarunt, in requirendo laborare quid opus est? Neque enim fatigare nos debet incerta eorum habitudo uel pulchritudo, quorum erit certa et sempiterna damnatio. Nec moueat quomodo erit in eis corpus incorruptibile si dolere poterit, aut quomodo corruptibile si mori non poterit. Non enim est uera uita nisi ubi feliciter uiuitur, nec uera incorruptio nisi ubi salus nullo dolore corrumpitur. Vbi autem infelix mori non sinitur, ut ita dicam, mors ipsa non moritur; et ubi dolor perpetuus non interimit sed affligit, ipsa corruptio non finitur».

88 Cf. Augustinus Hipponensis, De civitate Dei 22, 19.

89 Cf. Augustinus Hipponensis, Enchiridion ad Laurentium de fide, spe et caritate 84-87; idem, Sermo 241, 1. 
6. La seconda venuta del Signore e il giudizio universale nel pensiero patristico posteriore $^{90}$. Il millenarismo concepiva il millennio di Cristo secondo il modo con cui Cristo dopo la sua risurrezione appariva ai discepoli: si mangerà e si berrà come il Cristo faceva; più tardi, quando il male sarà stato del tutto sconfitto, i giusti subiranno un'ultima trasformazione. Si può comprendere il successo di simili teorie e speculazioni rivestite di un materialismo infantile. Papia, ad esempio, parla di grappoli enormi che si disputeranno il privilegio di rimpinzare i santi:

«Verranno giorni, nei quali nasceranno viti con diecimila tralci ciascuna e in ciascun tralcio diecimila bracci e in ciascun braccio diecimila ramoscelli e in ciascun ramoscello diecimila grappoli e in ciascun grappolo diecimila acini, e ciascun acino spremuto produrrà venticinque misure di vino ${ }^{91}$. E quando uno dei santi coglierà un grappolo, un altro grappolo griderà: Io sono migliore, prendi me, per mezzo mio benedici il Signore» ${ }^{92}$.

Lo stretto letteralismo che diede origine a siffatte fantasticherie, non è solamente un'eredità delle forme più banali del messianismo veterotestamentario; vi si trova anche un primissimo effetto della lettura dei testi biblici fatta senza avvertire il senso preciso dei generi letterari della Bibbia. Infatti, i generi letterari biblici sono così differenti dai quelli greci, che essi non sanno più esercitare una cernita tra le immagini e le realtà che esse ricoprono. Dionigi di Alessandria, per combattere il millenarismo, si appellò al suo maestro Origene e negò l'autenticità dell'Apocalisse ${ }^{93}$, con la conseguenza che nel IV secolo il millenarismo fu quasi completamente abbandonato dai cattolici. Conosciamo solamente un unico difensore orientale di questa dottrina: Apollinare di Laodicea ${ }^{94}$, condannato come eretico.

Fra gli occidentali l'Ambrosiaster vede nella caduta dell'Impero Romano il segno dell'imminente fine del mondo: sarebbe allora venuto l'Anticristo e, in seguito, Dio l'avrebbe annientato, e Cristo con i santi avrebbe iniziato a regnare per mille anni ${ }^{95}$.

Sant'Agostino condivise, per un certo tempo, il millenarismo ${ }^{96}$, ma più tardi rinunciò a tale dottrina a causa di tutte quelle strane e grossolane teorie

${ }^{90}$ Per quanto riguarda la problematica trattata in questo paragrafo, cf. J.N.D. Kelly, Il pensiero cristiano delle origini, Bologna 1972, 583-590.

91 Una misura (una metreta) equivale a litri $38,88$.

92 Il testo di Papia è citato da: Irenaeus Lugdunensis, Adversus haereses V 33, 3, SCh 153, 414 (il testo è stato ripubblicato in C. Nardi [ed.], op. cit., 158).

93 Cf. Eusebius Caesariensis, Historia ecclesiastica 7, $24 \mathrm{~s}$.

${ }^{94}$ Cf. Basilius Caesariensis, Epistula 263, 4; J.N. Guinot, Théodoret et le millenarisme d'Apollinaire, ,Annali di storia dell' esegesi” 15(1998) n. 1, 153-180; E. Prinzivalli, Il Millenarismo in Oriente da Metodio ad Apollinare, ibidem, 125-151.

95 Cf. Ambrosiaster, In II ad Thessalonicenses 8 s.; idem, In I ad Corinthios 15, 52. 
che l'accompagnavano. Il vescovo d'Ippona cominciò, quindi, a spiegare il brano apocalittico in questione interpretandolo in modo allegorico, ove la prima risurrezione sarebbe consistita nella liberazione dalla morte del peccato e nell'invito alla vita davvero evangelica, e il Regno di Cristo con i suoi eletti dovrebbe essere compreso nel senso della missione della Chiesa in terra. Inoltre, i mille anni del Regno andrebbero intesi come il tempo di mille anni che precede il giudizio universale, oppure - preferibilmente - come la durata totale della Chiesa sulla terra ${ }^{97}$.

${ }^{96}$ Cf. Augustinus Hipponensis, De civitate Dei XX 7, 1, CCL 48, 709: «Qui propter haec huius libri uerba primam resurrectionem futuram suspicati sunt corporalem, inter cetera maxime numero annorum mille permoti sunt, tamquam oporteret in sanctis eo modo uelut tanti temporis fieri sabbatismum, uacatione scilicet sancta post labores annorum sex milium, ex quo creatus est homo et magni illius peccati merito in huius mortalitatis aerumnas de paradisi felicitate dimissus est, ut, quoniam scriptum est: unus dies apud dominum sicut mille anni, et mille anni sicut dies unus, sex annorum milibus tamquam sex diebus impletis, sequatur uelut septimus sabbati in annis mille postremis, ad hoc scilicet sabbatum celebrandum resurgentibus sanctis. Quae opinio esset utcumque tolerabilis, si aliquae deliciae spiritales in illo sabbato adfuturae sanctis per domini praesentiam crederentur. Nam etiam nos hoc opinati fuimus aliquando»; idem, Sermo 259, 2, PL 38, 1197 : «Regnabit enim Dominus in terra cum sanctis suis, sicut dicunt Scripturae, et habebit hic Ecclesiam, quo nullus malus intrabit, separatam atque purgatam ab omni contagione nequitiae; quam significant centum quinquaginta tres illi pisces, de quibus iam, quantum memini, aliquando tractavimus»; M. Grazia Mara, Agostino e il millenarismo, ,Annali di storia dell' esegesi” 15(1998) n. 1, 217-230.

${ }_{97}$ Cf. Augustinus Hipponensis, De civitate Dei XX 6, 1, CCL 48, 706-707: «Deinde adiungit et dicit: „Amen, amen dico uobis, quia uenit hora et nunc est, quando mortui audient uocem Filii Dei, et qui audierint uiuent. Sicut enim Pater habet uitam in semet ipso, sic dedit et Filio habere uitam in semet ipso". Nondum de secunda resurrectione, id est corporum, loquitur, quae in fine futura est, sed de prima, quae nunc est. Hanc quippe ut distingueret, ait: „Venit hora, et nunc est”. Non autem ista corporum, sed animarum est. Habent enim et animae mortem suam in impietate atque peccatis, secundum quam mortem mortui sunt, de quibus idem Dominus ait: „Sine mortui mortuos suos sepeliant"; ut scilicet in anima mortui in corpore mortuos sepelirent. Propter istos ergo impietate et iniquitate in anima mortuos: „Venit, inquit, hora, et nunc est, quando mortui audient uocem Filii Dei; et qui audierint, uiuent". Omnes itaque mortui sunt in peccatis, nemine prorsus excepto, siue originalibus siue etiam uoluntate additis, uel ignorando uel sciendo nec faciendo quod iustum est; et pro omnibus mortuis uiuus mortuus est unus, id est nullum habens omnino peccatum; ut, qui per remissionem peccatorum uiuunt, iam non sibi uiuant, sed ei, qui pro omnibus mortuus est propter peccata nostra et resurrexit propter iustificationem nostram, ut credentes in eum, qui iustificat impium, ex impietate iustificati, tamquam ex morte uiuificati, ad primam resurrectionem, quae nunc est, pertinere possemus»; ibidem XX 7, 2, CCL 48, 710: «Mille autem anni duobus modis possunt, quantum mihi occurrit, intellegi: aut quia in ultimis annis mille ista res agitur, id est sexto annorum miliario tamquam sexto die, cuius nunc spatia posteriora uoluuntur, secuturo deinde sabbato, quod non habet uesperam, requie scilicet sanctorum, quae non habet finem, ut huius miliarii tamquam diei nouissimam partem, quae remanebat usque ad terminum saeculi, mille annos appellauerit eo loquendi modo, quo pars significatur a toto; aut certe mille annos pro annis omnibus huius saeculi posuit, ut perfecto numero notaretur ipsa temporis plenitudo»; ibidem XX 9, 1, CCL 48, 715: «Interea dum mille annis ligatus est diabolus, sancti regnant cum Christo etiam ipsi mille annis, eisdem sine dubio et eodem modo intellegendis, id est isto iam 
Vediamo ora il pensiero circa il giudizio universale, che in quel periodo occupava un posto molto importante. Le presentazioni scritturistiche del giudizio universale sono quasi sempre prese letteralmente. Ciò si nota specialmente nel pensiero dei Padri latini, la cui teologia era tendenzialmente più arcaica rispetto a quella greca, la quale interpretava tale evento anche in chiave spirituale. E così, per san Basilio, i veri accusatori saranno i nostri peccati ${ }^{98}$, e i nostri cuori colpevoli saranno illuminati divinamente dallo stesso CristoGiudice $^{99}$. Anche per il Nazianzeno il vero significato del giudizio sta nella leggerezza o nella pesantezza dei peccati che gravano sulla coscienza ${ }^{100}$. Infatti, saranno gli stessi nostri peccati ad accusarci e noi stessi ci condanneremo ${ }^{101}$. Sotto l'influsso greco, sant'Ambrogio ebbe la stessa opinione. Secondo lui, infatti, i libri che saranno aperti nel giorno del giudizio simboleggiano la nostra coscienza; parimenti, devono essere interpretati simbolicamente anche il trono del divino giudice e gli Apostoli che assistono al processo. La sentenza finale pronunciata da Cristo-Giudice significa la ratifica dei meriti di ogni persona ${ }^{102}$. A dir il vero, anche sant'Agostino vede nel libro che sarà aperto la coscienza di ogni uomo le cui azioni riemergeranno tutti insieme nel ricordo ${ }^{103}$. Di regola, però, sembra che egli si limiti ad accettare il testo letterale della Bibbia.

Per giustificare il giudizio finale, i Padri insegnavano di solito che, dato che durante la vita terrena non esiste vera giustizia, bisogna supporre che essa avverrà nel mondo futuro. Infatti, Iddio annota in un libro tutto ciò che operiamo, affinché ne rendiamo conto nell'aldilà ${ }^{104}$. Sant'Atanasio insegna-

tempore prioris eius aduentus. Excepto quippe illo regno, de quo in fine dicturus est: uenite, benedicti Patris mei, possidete paratum uobis regnum, nisi alio aliquo modo, longe quidem impari, iam nunc regnarent cum illo sancti eius, quibus ait: ecce ego uobis cum sum usque in consummationem saeculi: profecto non etiam nunc diceretur ecclesia regnum eius regnum que caelorum».

98 Cf. Basilius Caesariensis, Homilia in Psalmum 48, 2.

99 Cf. Basilius Caesariensis, Homilia in Psalmum 33, 4.

100 Cf. Gregorius Nazianzenus, Carmina 34, $254 \mathrm{~s}$.

101 Cf. Gregorius Nazianzenus, Oratio 16 [In Patrem tacentem], 8, PG 35, 944-945: «Tí

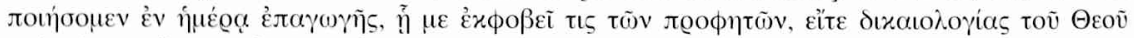

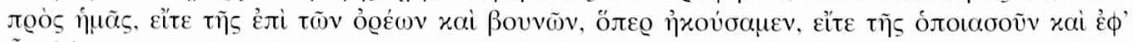

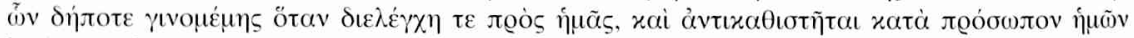

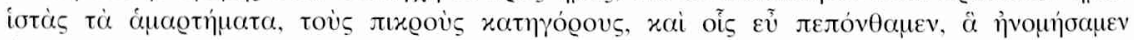

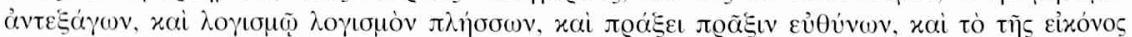

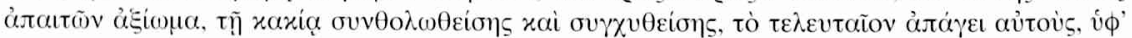

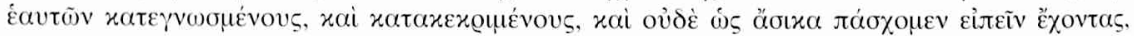

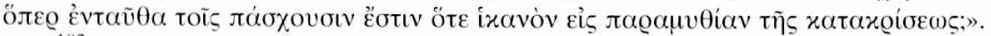

${ }^{102}$ Cf. Ambrosius Mediolanensis, Epistula 2, 9 s.; idem, Epistula 73, 3.

103 Cf. Augustinus Hipponensis, De civitate Dei XX 14, CCL 48, 724: «Quaedam igitur uis est intellegenda diuina, qua fiet, ut cuique opera sua, uel bona uel mala, cuncta in memoriam reuocentur et mentis intuitu mira celeritate cernantur, ut accuset uel excuset scientia conscientiam atque ita simul et omnes et singuli iudicentur».

${ }^{104}$ Cf. ad es. Gregorius Nazianzenus, Oratio 19, 15; Cyrillus Hierosolymitanus, Catechesis 18, 4; Ambrosiaster, In Romanos 2, 3, 6; Iohannes Chrysostomus, De diabolo tentatore hominis 1, 8. 
va che proprio durante il giudizio finale ogni uomo dovrà rendere conto delle sue azioni compiute sulla terra ${ }^{105}$. La tradizione tipicamente latina sosteneva che, anche se tutti dovranno comparire davanti al tribunale di Cristo nell'ultimo giorno, saranno giudicati i cristiani tiepidi non i giusti, perché questi ultimi non hanno bisogno di essere giudicati. Gli empi, invece, sono stati già giudicati, come attesta la Scrittura: «I malvagi non risorgeranno nel giudizio" (Sal 1,5); "Chi crede in Lui non è giudicato, ma chi non crede è già giudicato» $(\mathrm{Gv} 3,18)^{106}$. Nella tradizione occidentale, in particolare sant'Agostino, emerge un insegnamento leggermente diverso, in quanto sostiene che Dio ci giudica continuamente durante la nostra vita terrena, ma dal momento che ciò non è sempre chiaro per l'uomo - il Giudice ha stabilito un giorno in cui la sua giustizia si renderà manifesta a tutti ${ }^{107}$. Infatti, tutta la Scrittura dimostra che saremo giudicati da Cristo ${ }^{108}$. Anche sant'Agostino interpretò la parusia in senso allegorico come il regno di Cristo nella Chiesa; inoltre egli la intendeva anche come la venuta del Signore alla fine dei tempi ${ }^{109}$. In quel momento, saranno giudicati tutti gli uomini senza alcuna eccezione $^{110}$.

Ora, vediamo la sorte dell'uomo subito dopo la morte: che cosa succede nell'intervallo tra il decesso e il giudizio finale o universale. L'insegnamento dei Padri greci in proposito è molto diverso e quasi confuso. Ad esempio, san Cirillo di Alessandria, spiegando la parabola dell'epulone e del povero Lazzaro, dice che il testo prefigura il giudizio futuro alla risurrezione ${ }^{111}$, ma in altri scritti parla anche dell'ingresso diretto dei giusti nel cielo e delle pene immediate dei cattivi ${ }^{112}$. Più chiaro è san Giovanni Crisostomo ${ }^{113}$, che parla nettamente della ricompensa subito dopo la morte e, poi, anche al momento del giudizio universale ${ }^{114}$. Immediatamente dopo la morte, infatti, tutti saranno giudicati $^{115}$. La parabola, invece, del ricco epulone e del povero Lazzaro va

105 Cf. Athanasius Alexandrinus, Apologia contra Arianos 35.

106 Cf. ad es. Hilarius Pictaviensis, Tractatus super Psalmos 1, 15-18; Ambrosius Mediolanensis, In I ad Corinthios 15, 51-53; Zeno Veronensis, Tractatus 2, 21.

107 Cf. Augustinus Hipponensis, De civitate Dei XX 1-5.

108 Cf. Augustinus Hipponensis, De civitate Dei XX 30.

109 Cf. Augustinus Hipponensis, Epistula 199, 41-45.

110 Cf. Augustinus Hipponensis, De civitate Dei XX 21, 3; idem, Epistula 193, 11; idem, De agone Christiano 29; idem, Tractatus in Evangelium Iohannis 19, 18; ibidem, 43, 9.

111 Cf. Cyrillus Alexandrinus, In Lucam 16, 19.

112 Cf. Cyrillus Alexandrinus, De adoratione in spiritu et veritate 6; idem, Homiliae Paschales 1, 2; idem, In Psalmos 48, 16.

113 Per quanto riguarda l'escatologia di san Giovanni Crisostomo, cf. F. Leduc, L'eschatologie, une préoccupation centrale de saint Jean Chrysostome, „Proche Orient Chrétien” 19(1969) 109-134; L. Brottier, La résurrection, source et but de la spiritualité chrysostomienne. La résurrection est-elle un retour au Paradis?, „Connaissance des Pères de l'Église” 43(1991) 16-19.

114 Cf. Iohannes Chrysostomus, Homilia in II ad Timotheum 3, 3.

115 Cf. Iohannes Chrysostomus, Homilia in I ad Corinthios 42, 3. 
interpretata nel senso che la ricompensa divina sarà data subito dopo la morte, sia ai buoni che ai malvagi ${ }^{116}$.

L'insegnamento dei Padri occidentali in proposito è più chiaro e preciso, anche se - a dir il vero - nessuno di loro prima di san Girolamo considerò la sistemazione provvisoria di ricompense e di pene come un vero e proprio giudizio. Infatti, Sant'Ilario di Poitiers, ad esempio, sostiene che i buoni trovano il loro riposo eterno nel seno di Abramo, mentre i cattivi iniziano a subire la giusta pena che verrà ratificata durante il giudizio finale ${ }^{117}$. Sant'Ambrogio, basandosi sul II Libro di Esdra $(7,32)$, parla dei «depositi» (promptuaria) ove i morti aspettano la sentenza che sarà espressa durante il giudizio universale. Ciò nonostante, essi già la pregustano ${ }^{118}$. Il menzionato san Girolamo, invece, disse chiaramente che nelle singole persone al momento della morte si compie ciò che è riservato per tutti gli uomini nel giorno del giudizio universale ${ }^{119}$. In altri passi, egli identifica addirittura il giudizio finale con il momento della morte ${ }^{120}$. Per sant'Agostino, invece, dopo la morte le anime - conformemente alla loro vita terrena - subiscono le pene oppure riposano in pace ${ }^{121}$. Il vescovo di Ippona riservava l'espressione "giorno del giudizio» strettamente per giudizio finale ${ }^{122}$.

Circa l'inferno, generalmente tutti i Padri insegnavano che le pene dei dannati non avranno mai fine. E così, sant'Ilario di Poitiers parla dell'eternità dell'inferno di fuoco ${ }^{123}$. Anche san Basilio dice che, dal momento che le anime

116 Cf. Iohannes Chrysostomus, Homilia de Lazaro 1, 11; 2, 2 s.; 5, 3; 6, 6; 7, 4.

117 Cf. Hilarius Pictaviensis, Tractatus super Psalmos 2, 48; 51, 22 s.; 57, 5.

118 Cf. Ambrosius Mediolanensis, De bono mortis 45-47.

119 Cf. Hieronymus, In Ioel 2, 1.

${ }^{120}$ Cf. Hieronymus, In Isaiam 13, 6-9.

121 Cf. Augustinus Hipponensis, De praedestinatione sanctorum 24, PL 44, 977: «Hoc autem medio tempore inter depositionem et receptionem corporis, secundum ea quae gesserunt per corporis tempus, sive cruciantur animae, sive requiescunt»; idem, Enchiridion ad Laurentium de fide, spe et caritate 29,109, CCL 46,108: «Tempus autem quod inter hominis mortem et ultimam resurrectionem interpositum est, animas abditis receptaculis continet, sicut unaquaeque digna est uel requie uel aerumna pro eo quod sortita est in carne dum uiueret».

122 Cf. Augustinus Hipponensis, De vera religione 27, CCL 32: «Cuius populi uita interim temporalis incipit a Domini aduentu in humilitate usque ad diem iudicii, quando in claritate uenturus est»; idem, In Iohannis epistulam ad Parthos tractatus 4, PL 35, 2008: «Secundum id vero quod verbum caro factum est poterunt et mali quia in die iudicii videbunt et mali, quia sic veniet iudicaturus quomodo venerat iudicandus»; idem, Enarrationes in Psalmos 6, 1, CCL 38, 27: «Visum est autem nonnullis diem iudicii significare, id est tempus aduentus Domini nostri, quo uenturus est iudicare uiuos et mortuos"; idem, Enchiridion ad Laurentium de fide, spe et caritate 17, 66, CCL 46, 85: «Multa etiam hic uidentur ignosci et nullis suppliciis uindicari, sed eorum poenae reseruantur in posterum - neque enim frustra ille proprie dicitur dies iudicii quando uenturus est iudex uiuorum atque mortuorum - sicut e contrario uindicantur hic aliqua, et tamen si remittuntur profecto in futuro saeculo non nocebunt».

123 Cf. Hilarius Pictaviensis, Tractatus super Psalmos 51, 19; ibidem, 55, 4; idem, In Matthaeum $4,12$. 
dei malvagi nell'inferno sono del tutto separate dall'azione dello Spirito Santo, esse non potranno mai ravvedersi e pentirsi e, quindi, la loro pena è eterna. Il vescovo di Cesarea in Cappadocia sostiene che la maggioranza dei semplici cristiani è stata ingannata dal Diavolo, al punto di pensare che le pene dei dannati finiranno un giorno ${ }^{124}$. Anche per san Giovanni Crisostomo le pene dei dannati non avranno mai fine e non saranno in alcun modo alleviate ${ }^{125}$.

Alcuni teologi dell'antichità cristiana, però, insegnarono che, in qualche modo, le pene dei dannati non saranno eterne. Fra questi possiamo annoverare san Gregorio di Nazianzo, il quale sembra a volte domandarsi se la punizione che non avrà mai fine possa essere degna del Dio buono e misericordioso ${ }^{126}$. Da parte sua, san Gregorio di Nissa - senza dubbio sotto l'influsso di Origene prevede per i cattivi una purificazione finale, la loro conversione a Dio e addirittura la restaurazione finale e definitiva dell'universo (Diavolo compreso) ${ }^{127}$. Bisogna precisare, però, che lo stesso Nisseno a volte menziona anche le pene eterne delle anime dannate ${ }^{128}$. A partire dal V secolo, però, si stabilì quasi dappertutto in Oriente la dottrina secondo cui le pene dei dannati non avranno mai fine ${ }^{129}$. Per quanto riguarda l'Occidente in questo stesso periodo, il pensiero circa l'inferno e le sue pene era molto più variegato e sviluppato. E così, troviamo nell'Ambrosiaster una dottrina particolare che sembra una via di mezzo tra le due posizioni opposte. Per lui, infatti, soltanto i veri malvagi saranno puniti eternamente, mentre le pene dei peccatori cristiani saranno temporanee ${ }^{130}$. Sant'Agostino ci informa che, in quel periodo, in Occidente, erano presenti diverse dottrine in proposito: secondo alcuni i castighi nell'inferno sarebbero temporanei per tutti, senza alcuna distinzione; per altri, grazie all'intercessione dei santi i dannati possono salvarsi; per altri ancora, si salveranno coloro che (anche se eretici) erano sono stati battezzati ed avevano ricevuto l'Eucaristia, o comunque avevano ricevuto i sacramenti nella Chiesa cattolica; per altri, poi, saranno salvati tutti i cattolici, anche se non erano sempre vissuti virtuosamente; altri, infine, sostenevano che saranno eternamente puniti soltanto quei malvagi che durante la vita non praticavano l'elemosina ${ }^{131}$. Lo stesso Agostino, invece, contrasta queste opinioni ${ }^{132}$, sostenendo chiaramente che il fuoco inestinguibile

${ }^{124}$ Cf. Basilius Caesariensis, Regulae brevius tractatae 267.

125 Cf. Iohannes Chrysostomus, Ad Theodorum lapsum 1, 9 s.; idem, In Psalmos 49, 6.

${ }^{126}$ Cf. Gregorius Nazianzenus, Oratio 40, 36.

127 Cf. Gregorius Nyssenus, Oratio catechetica magna 26, 35; idem, De anima et resurrectione, PG 46,$72 ; 104-105 ; 152 ; 157$.

${ }_{128}$ Cf. Gregorius Nyssenus, Adversus eos qui castigationes aegre ferunt, PG 46, 312.

129 Cf. ad es. Cyrillus Alexandrinus, In Iohannem 3, 36; 9, 29; Theodoretus, In Isaiam 65, 20.

130 Cf. Ambrosiaster, In I ad Corinthios 15, 53.

131 Cf. Augustinus Hipponensis, De civitate Dei XXI 17-22.

132 Cf. Augustinus Hipponensis, Enchiridion ad Laurentium de fide, spe et caritate 29, 112 , CCL 46, 109: «Frustra itaque nonnulli, immo quam plurimi, aeternam damnatorum poenam et cruciatus sine intermissione perpetuos humano miserantur affectu, atque ita futurum esse non 
di cui parla il Signore è materiale e reale, anche se il «verme che non muove» di cui parla il Profeta Isaia $(66,24)$ può essere compreso in modo metaforico come il tormento del rimorso ${ }^{133}$. Il dolore dei bambini non battezzati sarà più leggero, anche se sarà ugualmente eterno ${ }^{134}$. Bisogna, però, aggiungere che anche sant'Agostino ammetteva per certi casi che alcuni peccatori cristiani potranno ottenere il perdono nell'aldilà. Lo basa sui testi neotestamentari: Mt 12, 32a ( «A chiunque parli contro il Figlio dell'uomo, sarà perdonato») e 1 Cor 3, 13-15 («[...] l'opera di ognuno sarà messa in luce; perché il giorno di Cristo la renderà visibile; poiché quel giorno apparirà come fuoco; e il fuoco proverà quale sia l'opera di ciascuno. Se l'opera che uno ha costruito sul fondamento rimane, egli ne riceverà ricompensa; se l'opera sua sarà arsa, egli ne avrà il danno; ma sarà salvo; però come se egli stesso fosse passato attraverso il fuoco»); Agostino sostiene che potranno essere perdonati quei peccatori che, anche se cristiani nel cuore, sono rimasti coinvolti in amori terreni ${ }^{135}$. Ciò nonostante, dopo la morte essi saranno purificati da un fuoco purgante ${ }^{136}$.

7. La vita eterna dei salvati ${ }^{137}$. Origene insegnava che nell'aldilà i redenti conosceranno dallo stesso Dio la natura e le cause di tutto il cosmo. Più tardi, essi raggiungeranno ciò che è ineffabile e non può essere visto. Alla fine diventeranno intelligenze pure e contempleranno faccia a faccia le sostanze intelligibile e razionali. Nonostante conservino sempre una volontà libera, non peccheranno più, perché san Paolo dice: «L'amore non verrà mai meno» ${ }^{138}$; lo stesso Dio-Amore impedirà di peccare all'anima che ha imparato ad amare Dio in modo puro e integro ${ }^{139}$. Anche il grande Agostino sostiene che i santi, continuando ad esercitare il loro libero arbitrio, non peccheranno; anzi, tale libero arbitrio sarà finalmente davvero «libero», perché liberato dalla concupiscenza e dal piacere di peccare ${ }^{140}$.

credunt: non quidem scripturis aduersando diuinis, sed pro suo motu dura quaeque molliendo, et in leniorem flectendo sententiam quae putant in eis terribilius esse dicta quam uerius».

133 Cf. Augustinus Hipponensis, De civitate Dei XX 22; XXI 9, 2; XXI 10, 1.

134 Cf. Augustinus Hipponensis, Enchiridion ad Laurentium de fide, spe et caritate 93; 111; 113; idem, De civitate Dei XXI 16.

135 Cf. Augustinus Hipponensis, De civitate Dei XXI 26, 2.

${ }^{136}$ Cf. Augustinus Hipponensis, Enchiridion ad Laurentium de fide, spe et caritate 18, 69, CCL 46, 87: «Tale aliquid etiam post hanc uitam fieri incredibile non est, et utrum ita sit quaeri potest, et aut inueniri aut latere, nonnullos fideles per ignem quendam purgatorium, quanto magis minusue bona pereuntia dilexerunt, tanto tardius citiusque saluari; non tamen tales de quibus dictum est quod regnum dei non possidebunt, nisi conuenienter paenitentibus eadem crimina remittantur».

137 Per quanto riguarda la problematica trattata in questo paragrafo, cf. J.N.D. Kelly, $I l$ pensiero cristiano delle origini, Bologna 1972, 590-595.

138 Cf. Origenes, De principiis II, 11, 7; idem, In Iohannem 1, 16.

139 Cf. Origenes, In Romanos 5, 10.

${ }^{140}$ Cf. Augustinus, De civitate Dei XXII 30, 2 s. 
San Cirillo di Gerusalemme affermava che lo scopo dei cristiani è il raggiungimento della vita eterna, e questa consiste nel dimorare tutta l'eternità con $\mathrm{Dio}^{141}$. San Basilio sostiene che dopo la risurrezione i santi contempleranno Iddio faccia a faccia stando sempre nella sua dimora eterna ${ }^{142}$, vivendo l'amicizia fra di loro e con Dio ${ }^{143}$. San Gregorio di Nissa mette moltissimo in rilievo la deificazione che attende i redenti nella vita eterna: la nostra natura sarà dotata delle qualità divine, della perfezione, dell'onore, della potenza e della gloria ${ }^{144}$. San Gregorio Nazianzeno descrive la vita eterna come un'ininterrotta gioiosa festa, ove i redenti contempleranno la Trinità, diventeranno figli di Dio e saranno realmente deificati. Nella nostra condizione attuale, noi possiamo soltanto a stento e minimamente intuire l'enormità delle beatitudini che per noi sono riservate ${ }^{145}$.

Per sant'Ambrogio, la vita eterna è luogo di perfetto riposo, di gloria e di luce che non tramonta mai ${ }^{146}$. I santi godranno della comunione beata tra di loro e con $\mathrm{Dio}^{147}$. In quel periodo si diffonde l'idea che nella vita eterna potremo incontrare i santi che non avevamo mai potuto conoscere sulla terra, e potremo liberamente conversare con loro e così attuare con loro la «comunione dei santi» ${ }^{148}$. San Giovanni Crisostomo sostiene che la gioia e il premio più grande riservato ai giusti nella vita eterna consisterà nel vedere chiaramente e perfettamente Dio ${ }^{149}$, anche se non si potrà afferrare realmente l'essenza divina ${ }^{150}$, poiché ciò è prerogativa soltanto del Figlio di Dio e dello Spirito Santo ${ }^{151}$.

Sant'Agostino constata che nessuno scopo temporale può soddisfare l'uomo ${ }^{152}$, perciò la felicità finale ed eterna che i redenti, sia uomini che angeli, godranno nella loro vera patria - in cielo - consisterà nel conoscere e nell'amare la Trinità ${ }^{153}$. Tale esperienza è indescrivibile; ma si può dire soltanto che essi «nel corpo vedranno Dio». In un primo momento, però,

${ }^{141}$ Cf. Cyrillus Hierosolymitanus, Catechesis 18, 28-29.

142 Cf. Basilius, Homilia in Psalmum 33, 11.

143 Cf. Basilius, Homilia in Psalmum 28, 3; idem, Homilia in Psalmum 14, 1.

144 Cf. Gregorius Nyssenus, De anima et resurrectione, PG 46, 156-157.

145 Cf. Gregorius Nazianzenus, Oratio 7, 23; 24, 19; 43, 82.

146 Cf. Ambrosius Mediolanensis, De obitu Theodosii 30, 32; idem, De bono mortis 47.

${ }^{147}$ Cf. Ambrosius Mediolanensis, De obitu Theodosii 29, 31, 37, 39.

148 Cf. ad es. Ambrosius Mediolanensis, De obitu Valentiniani 71, 77; idem, De institutione virginis 113; Hieronymus, Epistula 39, 6-7; Nicetas Remesianensis, De symbolo 10.

149 Cf. Iohannes Chysostomus, Homilia in Epistulam ad Romanos 32, 3; idem, Homilia in I Epistulam ad Corinthios 34, 2.

${ }^{150}$ Cf. Iohannes Chysostomus, De beato Philogono 6, 1 .

151 Cf. Iohannes Chysostomus, Homilia in Evangelium Iohannis 15, 1.

152 Cf. Augustinus Hipponensis, De vita beata 11; idem, Confessiones 1, 1.

153 Cf. Augustinus Hipponensis, Tractatus in Evangelium Iohannis 26, 5; idem, De Trinitate VIII 4-8. 
sant'Agostino negò l'idea che i santi vedano Dio per mezzo dei loro occhi fisici ${ }^{154}$. Più tardi, invece, considerò ciò plausibile ${ }^{155}$ : dopo la risurrezione, gli occhi dei beati sarebbero glorificati e trasfigurati in modo tale da poter vedere Dio.

San Cirillo Alessandrino insegna che la nostra deificazione avrà l'apogeo dopo la seconda venuta del Signore e dopo la risurrezione finale ${ }^{156}$. Allora, la nostra intelligenza (vo) sarà ripiena della luce divina e avremo una conoscenza «abbagliante» contemplando apertamente la natura divina, e così saremo perfettamente felici ${ }^{157}$. Dopo la risurrezione finale, i nostri corpi non saranno più corruttibili, bensì incorruttibili e perfetti, senza alcuna debolezza, e anch'essi parteciperanno alla gloria di Cristo ${ }^{158}$.

Nei Padri latini si trova l'opinione secondo la quale la felicità della vita eterna avrà diversi livelli in proporzione ai meriti dei singoli individui ${ }^{159}$, ma, in quanto basati sul merito, non susciteranno alcuna gelosia ${ }^{160}$. Nella tradizione orientale troviamo Teodoreto di Cirro che sostiene la gradualità della felicità, conformemente ai meriti, espressa dalle parole del Signore che nella casa del Padre vi sono molte dimore ${ }^{161}$.

Per concludere, possiamo dire - seguendo l'insegnamento di sant'Agostino, l'esimio Padre della Chiesa latina e forse il più grande Padre della Chiesa in assoluto - che la massima gioia nell'aldilà consisterà nel lodare per tutta l'eternità Dio, fine di tutti i nostri desideri, colui che sarà venerato ininterrottamente, amato senza sosta e lodato senza alcuna stanchezza, noia o dispiace$\mathrm{re}^{162}$. La vita dopo la risurrezione finale sarà per i beati un riposo, un sabato

${ }^{154}$ Cf. ad es. Augustinus Hipponensis, Epistula 92, 6, CSEL 34/2, 443: «Ad hoc enim fide corda nostra mundantur, quia nobis fidei merces uisio dei promittitur. Quae si per corporis oculos erit, frustra ad eam percipiendam sanctorum animus exercetur, immo uero tam peruerse sentiens animus non exercetur in se, sed totus in carne est".

${ }^{155}$ Cf. Augustinus Hipponensis, De civitate Dei XXII 29, CCL 48, 859: «Sed quanto amplius tunc omnes munere isto abundabunt, cum Deus erit omnia in omnibus! Habebunt tamen etiam illi oculi corporei officium sum et in loco suo erunt, uteturque illis spiritus per spiritale corpus.

156 Cf. Cyrillus Alexandrinus, In Malachiam 4, 2 s.

157 Cf. Cyrillus Alexandrinus, In Iohannem 14, 4; idem, Glaphyra in Exodum 2, PG 69, 432.

158 Cf. Cyrillus Alexandrinus, In Lucam 5, 27; idem, In I Epistulam ad Corinthios 6, 15.

159 Cf. ad es. Hilarius Pictaviensis, Tractatus super Psalmos 64, 5. 17 s.; Ambrosius Mediolanensis, Epistula 7, 11; idem, Expositio Evangelii secundum Lucam prologus 6; 4, 37; 5, 61.

${ }^{160}$ Cf. Augustinus, De civitate Dei XXII 30, CCL 48, 863: «Atque id etiam beata illa ciuitas magnum in se bonum uidebit, quod nulli superiori ullus inferior inuidebit, sicut nunc non inuident archangelis angeli ceteri; tamque nolet esse unusquisque quod non accepit, quamuis sit pacatissimo concordiae uinculo ei qui accepit obstrictus, quam nec in corpore uult oculus esse qui est digitus, cum membrum utrumque contineat totius corporis pacata compago».

161 Cf. Theodoretus, In Canticum Canticorum 1, PG 81, 61.

162 Cf. Augustinus Hipponensis, De civitate Dei XXII 30, 1. 
che non conoscerà tramonto, nel quale essi saranno ripieni dell'amore, della benedizione e della presenza santificatrice di Dio ${ }^{163}$.

8. Rilievi conclusivi. Nell'antichità cristiana non è stata elaborata una sintesi dogmatica estensiva dei dati escatologici. Infatti, a parte il «Credo» del primo concilio ecumenico di Nicea (325) - che parla delle seconda venuta di Cristo, del giudizio universale e della risurrezione - l'età patristica non conosce formulazioni dogmatiche. Di fronte all'affermazione di tutta una serie di eventi, il commento teologico e la tradizione stessa non sono sufficientemente omogenei e chiari. Circa il periodo intermedio tra la morte e la risurrezione finale, i Padri mantengono un contemplativo silenzio di profonda ammirazione. Parlano del locus caelestis ove vivono le anime. I luoghi prossimi del Regno futuro sono più uno stato che un luogo topografico. Questo è l'Eden divenuto l'anticamera del Regno, chiamato anche «seno di Abramo», «luogo di luce, di ristoro e di riposo». Le anime purificate passano gradualmente da una mansio celeste all'altra, avvicinandosi all'Agnello. Si tratta, però, di una vita disincarnata. «I santi si riposano dalle loro fatiche, perché le loro opere li seguono» (Ap 14, 13). La preghiera dei viventi per i morti e dei morti per i vivi sostiene l'attesa e crea la communio sanctorum.

Il contributo dei Padri apologisti alla dottrina escatologica consiste anzitutto nell'aver mostrato ai filosofi pagani la ragionevolezza di certe teorie teologiche come il giudizio o la pena dell'inferno, indicandone i paralleli mitologici. In secondo luogo, essi fanno un proficuo uso di una teodicea naturale allorquando intendono spiegare il giudizio equo di Dio. In questa operazione si infiltrano nella primissima teologia cristiana alcune categorie filosofiche greche (specie platoniche o, meglio, medioplatoniche). Combattendo contro la gnosi, gli apologisti e i teologi del III secolo stabiliranno natura, fasi, scopo della nostra redenzione, inserendo in tal modo la speranza del mondo futuro in una tipica economia di salvezza.

Un notevole contributo allo sviluppo dell'escatologia viene dato dalla scuola teologica di Alessandria e, in seno ad essa, dal suo più famoso esponente, Origene. La sua critica al millenarismo e l'interpretazione simbolicoallegorica dei brani biblici relativi alla seconda venuta di Cristo, al giudizio universale e alle pene dell'inferno, contribuirono efficacemente ad una rilettura in chiave spirituale delle precedenti concezioni escatologiche. Il merito di Origene, inoltre, consiste nell'aver messo in grande rilievo l'individualizzazione del processo collegato con la speranza delle realtà ultime, che trova il suo corrispettivo nell'importanza che l'Alessandrino attribuisce al libero arbitrio dell'uomo.

163 Cf. Augustinus Hipponensis, De civitate Dei XXII 30, 4. 
Il pensiero escatologico di sant'Agostino - massimo esponente della teologia patristica latina - preferisce all'esegesi allegorica della scuola alessandrina un avvicinamento alla littera del testo ispirato. Egli s'interessa particolarmente allo stato intermedio che intercorre tra la morte e la risurrezione e il giudizio universale, al punto che alcuni autori moderni hanno voluto vedere in lui «l'inventore» del purgatorio ${ }^{164}$. Tale opinione è del tutto esagerata, perché della purificazione nell'aldilà parlarono anche prima di lui altri Padri, e specificamente greci ${ }^{165}$. Il vescovo d'Ippona basò il suo insegnamento circa la purificazione dopo la morte sulle preghiere liturgiche per i defunti ${ }^{166}$.

Se vogliamo, per concludere, paragonare il pensiero escatologico latino con quello greco, dobbiamo dire che tra di essi non si notano significative differenze, anche se - a onore del vero - i Padri latini sono in un certo senso più «curiosi» e vogliono scrutare, sempre maggiormente, le sorti dell'uomo nell'aldilà (in modo speciale sant'Agostino). Tale atteggiamento della teologia latina andrà sempre più sviluppandosi e contribuirà, nel medioevo, alla «nascita» del purgatorio ${ }^{167}$ con la sua «teologia penitenziale», come la definisce il padre Sergej Bułgakow ${ }^{168}$. I Padri greci, invece, di fronte al mistero escatologico restano ammiratamente «muti», lo professano, lo contemplano, lo vivono intensamente, lo celebrano liturgicamente, ma non vogliono scrutare ciò che è imperscrutabile, dal momento che la sapienza di Dio e la sapienza umana sono incompatibili, e soltanto la follia e la presunzione umane possono tentare di scrutare le inimmaginabili e le imprevedibili, meravigliose vie di Dio $^{169}$.

164 Cf. J.J. Gavigan, S. Augustini doctrina de purgatorio, „Ciudad de Dios” 167 (1954) 283296; J. Le Goff, La naissance du purgatoire, Paris 1981 (tr.it. Torino 1982); G. Filoramo, Escatologia, DPAC I 1210.

165 Cf. ad es. Cyprianus Carthaginensis, Epistula 55, 22; Ambrosius Mediolanensis, Enarrationes in XII Psalmos Davidicos 36, 26; Gregorius Nyssenus, Orationes de mortuis, PG 46, 851892.

166 Cf. ad es. Augustinus Hipponensis, De cura pro mortuis gerenda; idem, De octo Dulcitii quaestionibus 2; idem, De civitate Dei XXI 13 e 24.

167 Cf. J. Meyendorff, La teologia bizantina, Casale Monferrato 1984, 267-269.

168 Cf. P. Evdokimov, La donna e la salvezza del mondo, Milano 1980, 125; idem, L'Ortodossia, Bologna 1981, 470.

169 Cf. P. Evdokimov, La donna e la salvezza del mondo, Milano 1980, 125; idem, L'Ortodossia, Bologna 1981, 470. 


\section{ZARYS ESCHATOLOGII WCZESNOCHRZEŚCIJAŃSKIEJ}

(Omówienie)

Artykuł jest treścią wykładu, który został wygłoszony w ramach kursu interdyscyplinarnego pt. L'Escatologia cristiana verso il Terzo Millennio. Prospettive ecumeniche [= Eschatologia chrześcijańska w kierunku Trzeciego Tysiąclecia. Perspektywy ekumeniczne]. Kurs ten został zorganizowany przez Wyższy Instytut Nauk Religijnych «Mater Ecclesiae» Papieskiego Uniwersytetu św. Tomasza z Akwinu w Rzymie i odbywał się w roku akademickim 1997-1998. Artykuł ukazuje najstarszą chrześcijańską naukę eschatologiczną dotyczącą rzeczy ostatecznych: los człowieka po śmierci, powtórne przyjście Chrystusa, zmartwychwstanie umarłych, sąd ostateczny i żywot wieczny. Autor stara się jednocześnie przedstawić zachodzące w tym względzie podobieństwa i różnice pomiędzy Ojcami wschodnimi a zachodnimi. W artykule autor skupia się na okresie od początku piśmiennictwa patrystycznego aż do czasów św. Augustyna (+430), to znaczy na okresie, w którym chrześcijaństwo ściśle związane było z myślą starożytną, wykluczywszy jakikolwiek wpływ średniowiecza. 